\title{
VII.
}

\section{Die Orthopädie in ihren Heilerfolgen bei Pes varus}

unter besonderer Berïcksichtigung der von Dr. med. Gust. Krauss sen. in Darmstadt ausgebildeten Behandlungsmethode.

Von

Dr. med. Gustav Krauss jun.

\begin{abstract}
Die functionellen und formalen Resultate der operativen Orthopädie des Klumpfusses stehen aber weit zurück hinter jenen der rationellen, mechanischen Orthopädie, die ihr Ziel am wachsenden Fuss ansuahmslos auf einem zwar längeren, sber völlig ungefährlichen Wege erreioht. Lorenz.
\end{abstract}

Einleitung.

Die fruhzeitige und richtige Behandlung der Klumpfusse ist von so hervorragender Wichtigkeit und von so glänzendem Erfolge begleitet, dass jeder praktische Arzt sich dieser Aufgabe in vollem Maasse gewachsen zeigen sollte. Fugen wir noch die rachitischen Verkrummungen, die Skoliose und Kyphose hinzu, die ebenfalls nur bei frühzeitiger Erkenntniss und Behandlung vollkommen befriedigende Resultate ergeben, so haben wir damit die wichtigsten orthopädischen Anforderungen, die man an den Arzt zu stellen berechtigt ist, gekennzeichnet.

Alle diese Deformitäten zeigen sich dem beobachtenden Auge in so leicht erkennbarer Weise, dass das scharfe Auge des Hausarztes diese Gebrechen in ihren Anfängen, bevor er noch von den Angehörigen darauf aufmerksam gemacht und um deren Behandlung angegangen wird, erkennen und auf deren Beseitigung dringen sollte.

Esmarch sagt, dass er im Beginn seines klinischen Studiums auf seinen Wegen die Menschen auf etwaige Gebrechen hin beobachtet und über die zweckmässigsten therapeutischen Maassnahmen nachgedacht habe und dass er diese Methode jedem angehenden Klinicisten dringend empfehlen müsse. In erhöhtem Maasse gilt dies fur den praktischen Arzt; denn seine Aufgabe besteht viel mehr im frubzeitigen Erkennen und frühzeitigen therapeutischen Eingreifen, in der Prophylaxe ausgebildeter schwerer Krankheitsformen, als in der 
späteren Heilung letzterer durch eingreifende Operationen. Wie ungleich dankbarer gestaltet sich der Beruf des Arztes, wie viel mehr innere Befriedigung giebt er, wenn derselbe einen Menschen durch sachgemässe Behandlung in seinen Kinderjahren vor späteren Deformitäten und Functionsstörungen bewahrt, die ihm den Lebensgenuss entziehen und nachtheilig auf das Gemtith einwirken!

Auch ist noch der Secundärerscheinungen zu gedenken. So ist die Skoliose Ursache ungentugender Entwicklung der Lungen mit all ihren Folgen, der Entstehung von Beckenanomalien; der Klumpfuss beschränkt das Locomotionsvermögen, kann dasselbe in hochgradigen Fällen ganz aufheben und dadurch den damit Behafteten durch die behinderte Ortsbewegung schädigen.

Frühzeitig in Angriff genommen, lassen sich diese Deformitäten bei consequenter Behandlung von Seiten des Arztes und Ausdauer von Seiten des Patienten mit einfachen Mitteln beseitigen und dadurch die unheilvollen Folgen für die Zukunft abhalten.

Was aber speciell die frühzeitige Behandlung der Klumpfusse und rachitischen Verkrümmungen anbetrifft, von denen nur erstere Gegenstand dieser Abhandlung bilden sollen, so ist es eine dringende Forderung, dass die zu benutzenden Schienen und Maschinen möglichst einfach, leicht zu handhaben und billig in der Anschaffung sind, da es sich vorwiegend um Unbemittelte handelt und die Behandlung längere Zeit in Anspruch nimmt, wodurch eine öftere Erneuerung nothwendig wird.

\section{Bandagist und Arzt, ihre Stellung bei der Klumpfussbehandlung.}

Die Anfänge der Behandlung des angeborenen Klumpfusses futhren uns auf Hippokrates zurick, der dafur eine eigene Verbandmethode angab, die, wie Sayre ${ }^{3}$ ) uns mittheilt, sogar heute noch mit Vortheil benutzt werden könnte. Derselbe ist zugleich auch der Begrtinder der mechanischen Theorie für die Entstehung dieser Deformität, eine Theorie, welcher man sich in nenerer Zeit wieder zugewandt hat. Aufklärung tiber das Wesen des Klumpfusses brachten uns die pathologisch-anatomischen Arbeiten Scarpa's im Jahre 1803; zu einer wirksamen Behandlung fuhrte uns aber erst Stromeyer durch seine epochemachende Entdeckung der subcutanen Achillotenotomie, die wir allerdings der damals geltenden von Duverney be-

Anmerk. Die Zahlen beziehen sich auf das am Schlusse beigefügte Literaturverzeichniss. 
griindeten dynamishhen Theorie verdanken, die in Stromeyer und Dieffenbach energische Vertreter fand, aber heute verlassen ist.

Wie A dams in seiner grossen, 1864 mit dem ${ }_{n}$ Jacksonian Prize ${ }^{4}$ gekrönten Monographie: "Club-foot: its causes, pathology and treatment ${ }^{4}$, angiebt, lag vor Erfindung der Tenotomie die Behandlung des Klumpfusses gänzlich in den Händen der Bandagisten, an welche selbst die berïhmtesten Chirurgen, wie Sir Astl ey Cooper, die mit dieser Deformität Behafteten verwiesen. Das mechanische Moment spielt in der Behandlung eine so hervorragende Rolle und die Orthopädie steht zur Zeit noch so im Hintergrund des medicinischen Studiums, dass auch heutzutage noch vielfach der Bandagist sich die Behandlung der Klumpfüsse usurpirt, oder dass ihm dieses Gebiet freiwillig von dem praktischen Arzt tiberlassen wird.

Aehnlich erging es in der Augenheilkunde früher und ergeht es noch heutzutage zum Theil mit der Brillenverordnung, deren sich die Optiker bemächtigten.

Es ist klar, dass auf beiden Gebieten, dem der Verordnung von Fussmaschinen wie auch dem der Brillen, die Techniker, die nach der Schablone handeln und denen jede Einsicht und jede Richtschnur ihres Handelns fehlt, die häufigsten Missgriffe machen mïssen, und zwar zum Schaden derer, die ihnen ihr Vertrauen schenken.

Was den Klumpfuss anbetrifft, so liegt die Sache noch heute vielfach nicht viel besser wie vor Erfindung der Tenotomie. Fast jeder Instrumentenmacher grösserer Städte fertigt Klumpfussmaschinen nach irgend einem System, oft noch mit den ihm nöthig und zweckmässig erscheinenden Verbesserungen versehen, an. Selbst die Instrumentenmacher kleinerer Städte thun dies und bereisen sogar gelegentlich zu Zwecken des Absatzes die umliegenden Ortschaften, da diese Deformität ja häufig genug und auch bekannt genug ist. Letzteres geschieht z. B. von Speyer aus. Der weitere Gang der Dinge ist dann der, dass, nachdem die Eltern des betreffenden mit Klumfuss behafteten Kindes von der Stadt her das Modell eines sogenannten Scarpa'schen Schuhes erhalten haben, sie sich die folgenden Schienenschuhe von den Handwerkern ihres Dorfes für die Hälfte des Preises herstellen lassen.

Manchmal hat vor Beschaffung der Schienenschuhe eine orthopädische Behandlung mit Sa y r e'schem Heftpflasterverband oder Gypsverband, mit oder ohne T'enotomie, stattgefunden und blieb infolge mangelnder Ausdauer seitens des Kranken oder ungentigenden therapeutischen Eingreifens seitens des Arztes ohne Erfolg. Die Eltern and der kleine Patient gewöhnen sich an die Deformität, um so mehr, 
als die damit Behafteten oft nur wenig an der Locomotion gehindert sind. Man lebt sich in den Gedanken hinein, dieselbe sei unheilbar, und geht zum Schienenschuh uber, der immerbin eine gewisse Stütze beim Gehen abgiebt. In anderen Fällen haben die Eltern ärztliche Hulfe gar nicht in Anspruch genommen und sind gleich zum Schienenschuh tubergegangen.

König ${ }^{1)}$ spricht sich folgendermaassen aus:

nGar oft erlahmt aber vor Beendigung der Cur der Eifer des Arztes oder die Geduld der Eltern der kleinen Patienten. Die Neigung der Angehörigen, den jungen Erdenbtirger recht bald ans dem Verband heraus und in einen Schuh zu bringen, ist nicht selten auch von gewissenhaften Chirurgen unbesiegbar. Mit der zu frühen Anlegung des Schuhes ist aber, wenn die Eltern nicht sehr ängstlich sind, das Geschick des Klumpfusses entschieden. Er wird in den Schuh, so gut es gehen will, hineingedrickt, der Schuh verbirgt einen Theil des Schadens, ohne ihn zu corrigiren. Nach und nach stellt sich die alte Deformität wieder ein und sie wird bald bei dem auf dem äusseren Fussrand gehenden Patienten weit schlimmer, als sie war."

So kommt es, dass man, wenn man auf dem Lande reist, Klumpfusse findet, die trotz versuchter Behandlung noch za den hochgradigsten gehören; entweder war die Therapie wirkungslos, oder die Resultate gingen infolge unterbliebener Nachbehaindlung, für die der Schienenschuh kein Ersatz ist, verloren. An diesen Beispielen fehlt es auch in der Stadt durchaus nicht.

Die Ursache dieser Zustände liegt wesentlich in zwei Umständen :

1. dass die Orthopädie erst jetzt anfängt in ibrer Bedeutung für die praktische Medicin gewturdigt zu werden.

In Bezug hierauf sagt Sayre ${ }^{3}$ ):

${ }_{n}$ Da die Studenten keine Gelegenheit hatten, weder praktisch noch theoretisch unseren Gegenstand (die Ortbopädie) zu studiren, so waren die Fachgenossen im Ganzen kaum vorbereitet, die Deformitäten in erfolgreiche. Behandlung $\mathrm{zu}$ nehmen. Aus diesem Grunde wurden diese letzteren mehr Mechanikern tiberlassen, welche, wenn sie irgend einen Apparat construiren konnten, sich zugleich anmassten, jede Deformität uberhaupt heilen zu können."

"Der praktische Arzt, äussert sich Dr. Kra u ss 25), blieb ohne die erforderlichen Kenntnisse, um ein deformes Glied in seine normale Stellung zuritckzuftihren, und, gleichsam als wenn der menschliche Körper eine leblose Masse wäre, die nur mechanische Kräfte und Maassregeln erfordere, trat er seine Thätigkeit an den Mechaniker ab, der ebenso unbekannt ist mit dem inneren Bau der Körpertheile wie mit den Gesetzen, die das Leben beherrschen." 
2. dass es uns, worauf Herr Geh. Rath Czerny gelegentlich seiner klinischen Vorträge ganz besonders aufmerksam gemacht hat, an geschulten Technikern fehlt, welche die wissenschaftlichen Principien für die Wirkungsweise von Prothesen und Maschinen und die dabei in Betracht kommenden Gesetze kennen, die mit den anatomischen und physiologischen Verbältnissen des Körpertheiles, für den sie bestimmt sind, hinlänglich vertraut sind. Derartige Techniker können aber nur auf eigenen, speciell dafür bestimmten Lehranstalten ausgebildet werden. So lange diese fehlen, wird auch der Chirurg und Orthopäde durch die Unvollkommenheit gelieferter Apparate in seinen Bestrebungen gehemmt sein.

Was die Klumpfussschienen und -Maschinen anbelangt, so mussen wir uns von den Instrumentenmachern unabhängig, machen und zwar:

1. weil diese $\mathrm{zu}$ einem viel $\mathrm{zu}$ hohen Preise arbeiten, der bei der langen Dauer der Maschinenbehandlung und der nothwendigen häufigen Erneuerung der Maschinen und Schienen eine gründliche, bis zur definitiven Heilung fortgesetzte Behandlung unmöglich macht, da die zahlreichen Kranken in tiberwiegender Zahl zu den Unbemittelten gehören,

2. weil die Instrumentenmacher ohne das für jeden einzelnen Fall für den Erfolg nöthige Verständniss arbeiten.

„Da kaum eine Verkrimmung, sagt Dr. Krauss 25), genau gleich der anderen ist, so sollte der Arzt selbst mechanisches Erfindungstalent besitzen, um in besonderen Fällen die erforderlichen mechanischen Kräfte zur Wirkung zu bringen."

Die Schienen- und Maschinentheile für die orthopädische Behandlung des Klumpfusses muissen daher fabrikmässig in den gangbaren Grössen hergestellt und von jedem praktischen Arzt bezogen und fttr den betreffenden Fall zusammengesetzt und je nach der jeweilig nöthigen Correction zurecht gebogen werden können.

Dies ist der einzig mögliche Weg einer erfolgreichen mechanisehen Orthopädie bei Pes varus. -

Im Folgenden geben wir nun die Beschreibung von zwei Behandlungsmethoden*) bei Pes varus, die wir selbst näher kennen zu lernen Gelegenheit hatten.

*) Die dritte Behandlungsmethode, die wir zum Gegenstande eines eingehenderen Studiums machten, die der Heidelberger chirurgischen Klinik, beabsichtigen wir in Bälde nebst den gesammten auf Pes varus bezüglichen Fällen, welche in genannter Klinik in den letzten 10 Jahren behandelt wurden, in einer besonderen Arbeit zu veröffentlichen. 


\section{Leitende Grundsätze bei der derzeitigen Behandlung des Pes varus an der Würzburger chirurgischen Klinik.}

Herr Hofrath Schönborn sucht darauf hinzuwirken, dass die Kinder mit congenitalem Pes varus möglichst früh in Behandlung kommen, dass dieselbe 3-4 Wochen nach der Geburt beginnt. Jeder Tag ist zu dieser Zeit werthvoll. Die Schwierigkeiten der Behandlung steigern sich gradweise mit jedem Tag, der nach Ablauf der Geburt versäumt wird. Gleich nach der Geburt lassen sich die hochgradigsten Fälle von congenitalem Pes varus durch mechanische Orthopädie, und zwar oft ohne jede Tenotomie, corrigiren.

Einfache Hulfsmittel bewirken die Gradrichtung. Das ubliche Verfahren besteht darin, jeden Morgen dem Kinde einen Verband nach Sayre'scher Angabe zu machen, also mit einem Heftpflasterstreifen, der, von der Mitte des inneren Fussrandes bis zur Mitte des Oberschenkels an der Aussenseite reichend, den Fuss so in möglichst corrigirter Stellung festhält und durch circuläre Bindentouren befestigt wird. Reizt das Emplastr. adhaesivum die Haut, so wird statt desselben Empl. cerussae (auf Calico gestrichen) verwandt. Vor Anlegung des Verbandes lässt man passive Bewegungen des Fusses im Sinne der Correction machen und längere Zeit den Fuss in der corrigirten Stellung mit der Hand fixirt halten. Hiermit wird zweckmässigerweise Massage des Fusses verbunden. Sorgfältigste Pflege muss der Haut des Fusses zu Theil werden, namentlich denjenigen Stellen, die stärkerem Druck ausgesetzt sind. Ein solches Kind muss jeden Morgen nach Abnahme des Verbandes gebadet werden. Sind etwa geröthete Stellen infolge der Behandlung entstanden - zu Excoriationen oder Decubitalgeschwüren darf es bei sorgfältiger Behandlung nicht kommen -, so muss nach kalter Abwaschung ein Cerussapflaster auf diese Stellen gelegt werden. Hierdurch werden Decubitalgeschwüre, welche den Erfolg langer Behandlung vollständig vernichten können, sicher vermieden.

Inamovibele Verbände sind in diesem frïhen Lebensalter absolut zu vermeiden, da Herr Hofrath Schönborn von dem Grundsatz ausgeht, dass jeder circuläre Verband bereits nach 8 Tagen zu einer sicht- und messbaren Atrophie der Musculatur des Gliedes führt. Länger liegende feste Verbände haben unausbleibliche Ernährungsstörungen zur Folge und ist in diesem Sinne jeder den Fuss fixirende Apparat oder jede Maschine als ein Uebel für den Kranken zu betrachten. Gypsverbände werden deshalb bei ganz kleinen Kindern höchstens, wenn es sich um einen auswärtigen kleinen Patienten handelt, angelegt, und zwar auch nur für den Fall, dass dessen 
Mutter nicht zu bewegen ist, einige Tage zur Erlernung der Behandlung in der Klinik zu bleiben.

Die Kinder werden nicht eher entlassen, bis die Mutter das Redressement und die Anlage des Heftpflasterverbandes selbständig ausfibren kann.

Den Klumpfuss betrachtet man erst als geheilt, wenn nicht allein eine Correction, sondern sogar eine Uebercorrection erreicht ist; nur in diesem Fall ist man vor Recidiven einigermaassen gesichert. Immerhin ist es empfehlenswerth, noch für 1 oder 2 Jahre nach abgeschlossener Behandlung einen Scarpa'schen Stiefel tragen zu lassen.

Sind schon 6-8 Wochen nach der Geburt verstrichen, bevor die Behandlung beginnt, so kann es nothwendig sein, der eben beschriebenen Methode noch die Achillotenotomie hinzuzufugen.

Nach der Ansicht von Herrn Hofrath Schönborn kommt man auch beim Klumpfuss der Erwachsenen mit orthopädischen Maassnahmen und Sehnendurchschneidungen zum Ziel, indessen kann man in hochgradigen Fällen znweilen genöthigt sein, an Stelle einer langwierigen orthopädischen Therapie ein operatives Verfahren, entweder die Talusexstirpation oder vielleicht die noch wenig erprobte, aber gute Resultate versprechende Phelps'sche Methode zu setzen.

\section{Behandlungsmethode des Pes varus von Dr. Krauss in Darmstadt.}

Mit Rlicksicht auf den in den Verhandlungen der deutschen Gesellschaft für Chirurgie. XV. Congress, 4. Sitzungstag 10. April 1886 veröffentlichten Vortrag: "Ueber den Werth der Resection in der Fusswurzel zur Heilung des Klumpfusses", der sich im Auszug im Centralblatt fur Chirurgie. 1886. Nr. 24 Beilage findet, beabsichtige ich, im Folgenden vor Allem weitere Belege, die die daselbst niedergelegten Ansichten stutzen, sowie einige Ergänzungen zu bringen, bereits Mitgetheiltes aber nur insoweit zu wiederholen, als es zur richtigen Auffassung der ganzen Behandlungsmethode nöthig ist, damit der Leser sich ein vollständiges Bild uber die Krauss'sche orthopädische Klumpfussbehandlung machen kann.

K ö n ig ${ }^{1)}$ verlangt von einem Klumpfussverband, „dass derselbe uberall durch den Arzt herstellbar sei. Nur dadurch ist es möglich, die Klumpfüsse, deren Zahl gross ist, ohne Anwendung theuerer, vom Instrumentenmacher abhängiger Maschinen iberall zur Heilung zu bringen".

Zur Behandlung der Klumpftisse gehört 
1. ein allen Verhältnissen sich anpassendes System der Maschinenbehandlung;

2. ist es wtinschenswerth, dass die für den einzelnen Fall nöthigen Maschinen in entsprechender Grösse zur Verfügung stehen, um besondere Anfertigung zu umgehen.

Diese beiden Bedingungen finden ihre Anwendung anf die verschiedenen Stadien der Behandlung:

1. Herstellung der Formverbesserung (Klumpfussmaschinen);

2. Erhaltung derselben (Nachtmaschinen);

3. Unterstitzung dieser Stellung beim Gehen (Eisentheile fur Schienenschuhe).

Bisherige Fehlresultate rthren vielfach daher, dass man sich weder ther die Bedingungen, welchen die mechanische Behandlung zu genugen hat, noch uber die Mittel, diese Bedingungen zu erreichen, gentigende Rechenschaft gegeben hat. Die seitherige alleinige Anwendung des Gypsverbandes ohne Maschine hatte meistens keine Resultate oder nur ungentigende. Der Zügel von $\mathrm{Hueter}$ ist ungentigend, weil man damit den Fuss nicht in der nöthigen Correction halten kann. Die Heftpflasterstreifen verursachen leicht Hautreiz und sind nur vot schwacher Wirkung. Mit einer am Unterschenkel ver-

Fig. 1.

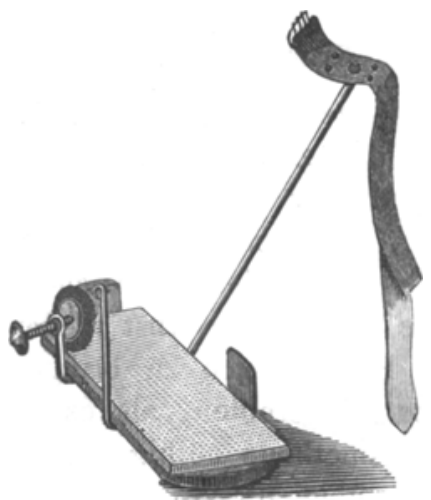

Krauss'sche Klumpfussmaschine (für den linken Fuss).

Seitenstange zur Correction der Supination gebogen. laufenden Holzschiene ohne zugehöriges Fussbrett kann man den Fuss wohl in Abduction bringen, aber nicht proniren und dorsalflectiren.

Dr. Krauss wendet seit 1856 ein aus Buchenholz gefertigtes Fussbrett mit biegsamer äusserer Seitenstange an, welch letztere so gebogen wird, dass dadurch die Supination, Adduction und Plantarflexion des Fusses corrigirt werden kann. Eine stellbare Schraube wirkt der Supination der Ferse entgegen (Fig. 1). Nachdem der Fuss durch Gypsbinden auf das mit einer Filzsohle versehene Fussbrett bandagirt worden ist, wird die Seitenstange, welche, wenn sie an der Aussenseite des Unterschenkels anliegt, den Fuss in die gewtinschte Correction gebracht hat, mit einem Lederband unter dem Knie befestigt. Gypsbinden ringförmig oberhalb der Knöchel angelegt und in Achtertouren um den Fuss gefuhrt, verhüten das Abgleiten des Fusses vom Fussbrett. 
Zur Anlegung des Verbandes dienen mit Gyps gut auf beiden Beiten eingeriebene Calicobinden, $90 \mathrm{Cm}$. lang und, je nachdem der Puss gross ist, $2^{1 / 2}-4^{1 / 2} \mathrm{Cm}$. breit. Der Verband wird ther die Strtimpfe angelegt und dadurch ein festes Anliegen bewirkt. Hueter ${ }^{2}$ ) sagt: „Auch ein überflussiges Ausfuttern mit Watte kann den engen Schluss des Verbandes und dadurch seine Wirksamkeit in Frage stellen." Der Fuss wird so auf das Fussbrett gestellt, dass die innere Seite der Ferse an der Fersenscheibe des Maschinchens anliegt. Es folgt die erste Bindentour, welche den Zweck hat, den Fuss, namentlich die Ferse, auf dem Fussbrett festzuhalten. Die 2. Binde fixirt den Bogen der äusseren Fussseite. Die 3. Binde bildet einen Ring ther der Ferse und bringt diesen Ring mit dem tibrigen Verband in Verbindung. Eine 4. Binde befestigt die Ferse an die Fersenscheibe. Bei Kindern im ersten Jahr gentigt diese Bindenzahl, während im späteren Alter mit Rücksicht auf den grösseren Umfang des Fusses und die Länge der Binden die Touren 1, 2 und 3 durch Verdoppelung verstärkt werden müssen.

Als allgemeine Bedingungen für die Maschinengypsbehandlung stellt Dr. Krauss die folgenden auf:

1. Eisen - und Holztheile düfen nicht direct am Fuss anliegen; wo dies nicht zu umgéhen ist, mtissen weiche $Z$ wischenlagen von Filz, Flanellstiuckchen u. s. w. den nachtheiligen Druck verhitten.

2. Die Maschine muss so anliegen, dass sie sich durch die Bewegungen des Kindes nicht von selbst löst.

3. Darf der Verband an keiner Stelle einen auf die Dauer unerträglichen Druck hervorrufen, oder Einschnürungen veranlassen.

4. Die Anlegung des Verbandes muss so einfach sein, dass auch die Angehörigen des Kindes sie erlernen können. Dies ist nöthig mit Rücksicht auf die sich immer auf einige Monate erstreckende Behandlung und wo es nicht wohl thunlich ist, die Kinder während so langer Zeit im Krankenhaus unterzubringen.

5. Der Verband muss die allmählich fortschreitende Gradrichtung des Fusses in möglichst wirksamer Weise herstellen.

Ad 2 sagt König $\left.{ }^{1}\right)$ :

„Bei Alledem (d. b. der Nothwendigkeit, möglichst bald nach der Geburt mit der Behandlung zu beginnen) bleibe ich aber dabei, dass es Fusschen giebt - ich meine die hochgradigen, ganz kurzen und sehr fetten Klumpfüsschen Neugeborener, bei welchen jede Methode der Behandlung fír die erste Zeit so gut wie nichts leistet. Je vollkommener man die Technik beherrscht, desto seltener werden freilich diese Fälle merden." 
König kommt dann zu dem Schlusse, dass man bei der Nothwendigkeit, die Behandlung der Klumpftisse bald nach der Geburt zu beginnen, und da sich Gypsverbände bei obigen Füsschen in dieser Zeit tiberhaupt nicht anlegen lassen, es nöthig sei, Verbände aus anderem Material zu fertigen.

Langjährige Erfahrung hat gezeigt, dass der Krauss'sche Maschinengypsverband, wenn richtig angelegt, auch unter obigen schwierigeren Verhältnissen liegen bleibt und die Gradrichtung bewirkt.

Hinsichtlich der Richtung, in welcher die Maschine wirken muss, sind dreierlei fehlerhafte Krummungsverhältnisse des Klumpfusses zu bekämpfen:

1. die Wendung der Zehen nach innen, die Adduction. Gegen diese wird einerseits auf der ganzen Innenseite des Fusses von Ferse bis grosse Zehe, andererseits auf der Aussenseite gegen die Convexität der Krümmung ein Druck ausgetibt. Die Supination der Ferse wird durch eine Fersenscheibe mit Schraube corrigirt.

2. die Supination durch Biegen der Seitenstange nach aussen.

3. die Plantarflexion durch Richten der Seitenstange nach vorn.

Der Verband bleibt Tag und Nacht liegen. Ein Wechsel des Verbandes ist erforderlich:

1. wenn der Verband lose geworden, eventuell durch Urin erweicht ist;

2. wenn Richtungsverbesserung nöthig ist.

In der Regel findet der Verbandwechsel in jedesmal möglichst verbesserter Richtung des Fusses alle 5-8 Tage statt.

Die Angehörigen der kleinen Patienten erlernen die Anlegung des Maschinengypsverbandes, wodurch eine ambulatorische Behandlung ermöglicht wird. Erneute Vorstellung ist circa alle 3-4 Wochen nöthig, damit die in der Behandlung nöthigen Aenderungen vorgenommen werden.

Die Gradrichtung wird durchschnittlich in 3-5 Monaten erzielt. Ist diese erreicht und der Fuss zum Gehen geeignet, so lässt man den Kranken am Tage mit Schnẗrschuh, der nach Bedurfniss mit Seitenstange versehen ist, gehen. Nachts wird eine Maschine angewendet, die aus Fussbrett und Seitenstange besteht und mit Bändern und Schnalle befestigt wird.

Die Nachbehandlung erstreckt sich auf mehrere Jahre. Am Tage wird für diese Zeitdauer der oben erwähnte Schnürschuh mit innerer*) seitlicher Schiene und Gelenk in der Höhe des Malleol. int. zur Unterstitzung beim Gehen getragen. Von dem unteren Theile

*) Man befestigt die Schiene auf der Innenseite, damit dieselbe als Anhalts- 
der 'Schienenstange geht ein Lederband ab, welches das Fussgelenk fixirt. In der Nacht werden Nachtmaschinen angelegt.

Der Maschinengypsverband wird in der Regel bei Klumpfusskranken bis zum Alter von 14-16 Jahren angewandt und ist deshalb zweckmässig, weil Aenderung in Lage und Spannung des Verbandes vom Kranken selbst nicht vorgenommen werden kann. Wo seitens des Kranken Verständniss und guter Wille die Behandlung unterstïtzen, tritt eine ähnliche mit Band und Schnalle zu befestigende Maschine an die Stelle und erlaubt häufigeren Wechsel in der Spannung des Verbandes durch frisches Anlegen.

Um den Druck des Fussbrettes gegen die Sohle des Fusses und den Druck des tiber den Fussrticken gelegten Gypsverbandes oder eventuell der Bänder zu verringern, werden Lagen von Flanell oder weicher Filz untergelegt.

Dr. Krauss stimmt mit allen Orthopäden in Folgendem überein:

1. die Behandlung des Klumpfusses sobald als möglich nach der Geburt zu beginnen,

2. bei hochgradigem Pes varus die Correction der Adduction in erster Linie, dann die der Adduction und Supination vorzunehmen und die Ausgleichung der Plantarflexion zuletzt zu bewirken. In den ersten Lebensmonaten kann man gegen alle drei Krïmmungsrichtungen gleichzeitig vorgehen.

Bezüglich der Tenotomie kommt im ersten Lebensalter nur die Achillotenotomie in Frage, jedoch mit der Maassgabe, dass es nicht rathsam ist, die Achillessehne fruber zu durchschneiden, als die Kinder anfangen zu laufen. Bis zu dieser Zeit lässt sich die Gradrichtung auf mechanischem Wege ohne erhebliche Schwierigkeit bewirken, und kann dann die Durchschneidung der Achillessehne nur das Mittel sein, einem noch vorbandenen geringeren Grade von Verkürzung zu begegnen. Bei Klumpfuss böheren Alters werden alle Sehnen und Bänder getrennt, die sich beim Versuch der Gradrichtung als gespannt erweisen; hierzu gehören die Sehnen des Tibialis ant. und post., Extensor halluc. long., Abductor halluc., Flexor digit. pedis brevis, Fascia plant. und Peronei.

Wenn die Gradrichtung eines Fusses sich über längere Zeit erstreckt und eine bereits durchschnittene Sebne einer weiteren Geradrichtung sich entgegensetzt, so durchschneidet Dr. Krauss dieselbe Sehne zum 2. und eventuell zum 3. Male. So muss bei hochgradigen Klumpfüssen im höheren Lebensalter die Achillotenotomie kann, mit welchem ein Druck auf die Aussenseite des Fusses ausgeübt werden soll. 
mehrmals gemacht werden. Die Durchschneidung der Sehne des Tibial. post. ist, wenn möglich, zu vermeiden, weil dieselbe die Abflachung des Fussgewölbes begunstigt. Gleiche Rücksicht gebührt der Fascia plant., indess ist Durchschneidung derselben in der Regel zur Gradrichtung nothwendig.

Dr. Krauss hat schon vor 50 Jahren, als er begann sich eingehender mit der Behandlung des Pes varus zu beschäftigen, die Nothwendigkeit erkannt, den jeweiligen Stand des Fusses durch Messung der Winkel der 3 fehlerhaften Krtmmungsrichtungen festzustellen, um einen bestimmten Anhaltspunkt iber Fortschritt und Ritckschritt in der Behandlung zu haben. Es ist dies eine Art orthopådischer Buchfuhrung. Esmarch macht bei der Skoliosenbehandlung in seiner Klinik darauf aufmerksam, wie wichtig es ist, von Zeit zu Zeit mittelst Bleidraht die jeweilige Krümmung der Wirbelsäule aufzunebmen und das Ergebniss der verschiedenen Untersuchungen nebeneinander auf Papier aufzuzeichnen, um durch Selbstcontrole über Fortschritt oder Rückschritt sich vor Täuschung zu bewahren. Wir glauben, dass jeder Orthopäde nur an der Hand genauer Messungen im Stande ist, die jeweiligen richtigen therapeutisehen Maassnahmen zu treffen. Die Messung soll dem Orthopäden zeigen, wie er sich etappenweise seinem Ziel, der Correction der Deformität, nähert.

Bei orthopädischen Curen, speciell denen des Fusses, ist es erwinseht, den Kranken vor der Behandlung photographiren zu lassen, und zwar in einer Stellung, welche die Deformität des Fusses in charakteristischer Weise zur Anschaung bringt. Zweitens lässt man einen Gypsabguss von dem Fuss nebmen, oder nimmt Abdrücke der Planta pedis auf. Photographie und Gypsabguss werden doppelt angefertigt, so dass sich beide Theile, die Angehörigen des Patienten und der Arzt, im Besitz derselben befinden und so den Ausgangspunkt der Behandlung, und am Patienten selbst den Status praesens sich jederzeit vor Augen führen können. Dies ist die kürzeste, anschaulichste und prägnanteste Krankengeschichte und ermuntert Arzt und Patient zur Ausdauer.

Zur Messung der 3 Winkel bei Pes varus muss der Fuss flach in bestmöglicher Stellung auf den Boden gesetzt werden. Man misst bei möglichster Correction, weil man nur dadurch immer denselben Winkel misst und damit vergleichbare Resultate erhält.

I. Winkel: Winkel der Dorsalflexion: Vorderer Winkel des Unterschenkels im Sagittalschnitt zum Boden bei grösstmöglicher Dorsalflexion des Fusses (Fig. 8 S. 199 für den linken Fuss). 
II. Winkel: Winkel der Supination: Innerer Winkel des Unterschenkels in Frontalschnitt zum Boden.

III. Winkel: Winkel der Adduction: Winkel der Sagittalschnitte von Fuss und Unterschenkel bei Gradrichtung.

Im Verhältniss wie die Gradrichtung fortschreitet, nähert sich dér anfänglich plantarflectirte Fuss, dessen $I$. Winkel tiber $90^{\circ}$ und $100^{\circ}$ betrug, dem rechten und dann dem spitzen Winkel; je kleiner der opitze Winkel wird, desto vollendeter ist die Correction.

Bei Messung des I. Winkels setzt man, wenn derselbe den rechten tberschreitet, den Fuss zurück, die Ferse muss beim Messen aber den Boden noch berühren.

Winkel II ist, wenn die Planta den Boden berihrt, infolge der fehlerhaften Supination kleiner als $90^{\circ}$; ist der rechte erreicht, so ist damit die Correction nahezu vollendet (vgl. Fig. 2 u. 3).

Winkel III: Bei ziemlicher Gradstellung fällt dieser Winkel zusammen und wird gleich Null; bei vollständiger Correction wird er negativ, indem unter normalen Verhältnissen eine durch die Medianlinie des Unterschenkels gelegte Linie in ihrer Verlängerung durch die Mitte der grossen Zehe geht.

Nach vollständiger Correction müssen Winkel I und II eine Excursion ergeben.

Dr. Krauss nimmt 3 Grade von Varus, je nach dem Grade der bestehenden Adduction und Supination, an:

1. Grad: Winkel III ist kleiner als $45^{\circ}$, es besteht also geringe Einwärtsdrehung. - Gehen auf äusserem Fussrand.

2. Grad: Adduction bis $45^{0}=1 / 2$ rechten. Der äussere Theil des Fussrückens wird znm Gehen benutzt.

3. Grad: Adduction, also Winkel III $=90^{\circ}$. - Gehen vollständig auf der äusseren Seite des Fussriickens.

Die Resultate der orthopädischen Behandlung des Pes varus durch die $\mathrm{Krauss}$ 'sche Maschinengypsbehandlung, combinirt mit Tenotomie, geben wir in Folgendem, indem wir zuerst die ausfuhrlichen Krankengeschichten von 9 Fällen und im Anschluss daran einen Ueberblick tiber die gesammten Heilresultate vom Jahre 1878 ab geben. Von diesen 9 Fällen ist der Fälle Bohn und Poh schon auf dem XV. Chirurgencongress kurz Erwähnung gethan, während daselbst die persönliche Vorstellung des Knaben Draudt erfolgte.

1. Georg Draudt, Sohn des Tagelöhners Georg Draudt in Gernsheim a/Rh. Geboren am 24. März 1876.

Pes varus cong. duplex 3. Grades (Fig. 2 u. 3 S. 198).

Das Kind war 2 mal in Spitalbehandlung; zum ersten Mal im ersten 
Lebensjahr, wo die Achillotenotomie gemacht wurde, dann im Alter von 3 Jahren für die Dauer von 3 Monaten, wo es zum zweiten Mal mit

Fig. 2.

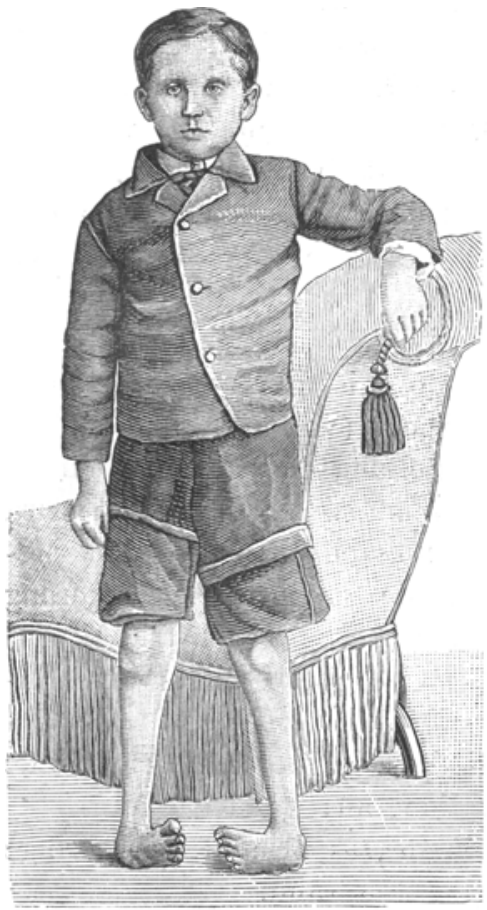

Vor der Behandlung. (Nach der photographischen Aufnahme.)
Fig. 3.

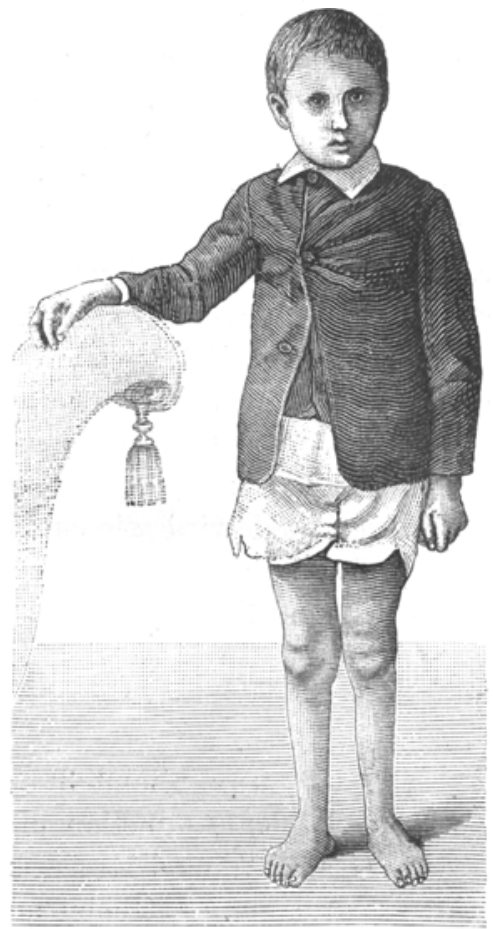

Nach der Behandlung. (Nach der photographischen Aufnahme.)

Achillotenotomie und Gypsverband behandelt und mit Schntirschuh und seitlicher Schiene bis zur Hufte entlassen wurde.

Fig. 4.

Fig. 5 .

Beiderseits Ferse in starker Supination.

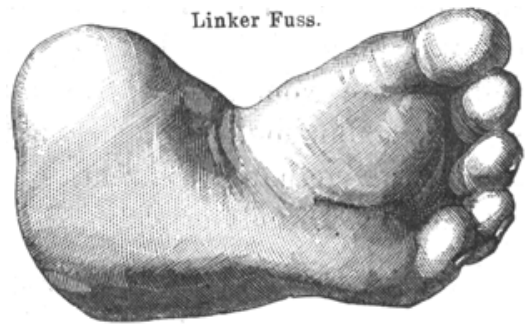

Rechter Fuss.

Gehflīche stark schattirt.

Formation der Fusssohlen. Adduction von $90^{\circ}$. (Nach Gypsabguss.) 
Status am 29. März 1884 bei Beginn der Krauss'schen Behandlung: Blonder Knabe, von ziemlich gesundem Aussehen, 8 Jahre alt.

Fig. 7.

Fig. 6.
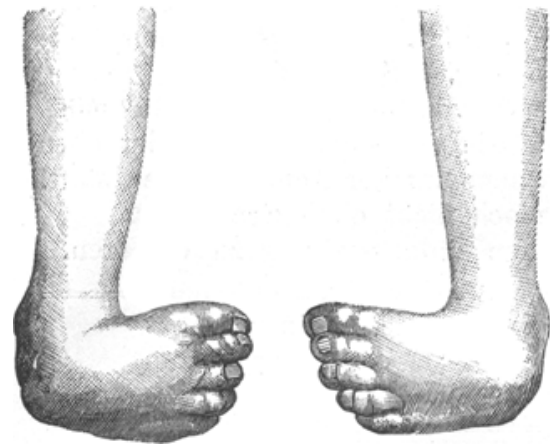

Vor der Behandlung. (Nach Gypsabguss.)

Der äussere Fussrand bildet einen Adductionswinkel von $90^{\circ}$, die Sohle steht senkrecht tiber dem Boden (Fig. 4 u. 5 S. 198 u. Fig. 6). Fascia plant. straff tiber der Hohlung des Fusses gespannt; im Fusse wenig Bewegliehkeit.

29. März. Durchschneidung der Fascia plant. beiderseits.

3. April. Beginn der Maschinengypsbehandlung.

29. April. Zweite Durchschneidung der Fascia plant. rechts.

1. Mai. Durchschneidung der Sehne des Abductor halluc. links.

12. Mai. Zweite Durchschneidung der Fascia plant. links und der Sehne des Abductor hall. rechts.

21. Juli. Durchschneidung der Sehnen des M. tibial. ant. beiderseits.

Die Sehnen des Tibial. post. wurden in diesem Fall nicht durchschnitten.

Links Anfangs April 1885, rechts Anfangs October 1885 Gradrichtung erreicht (Fig. 7), also links in 12,

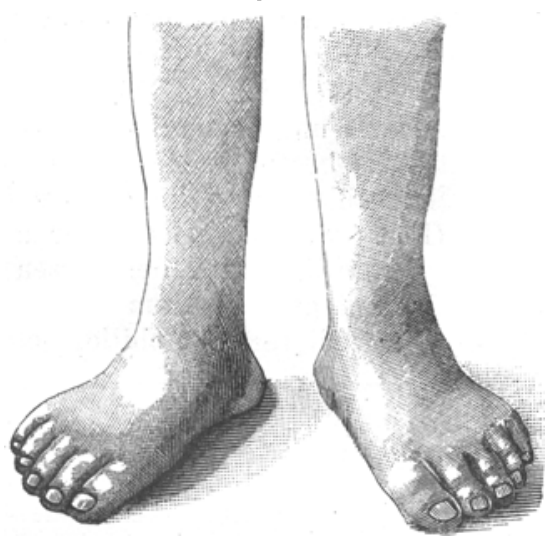

Nach der Behandlung. (Nach Gypsabguss.)

Fig. 8.

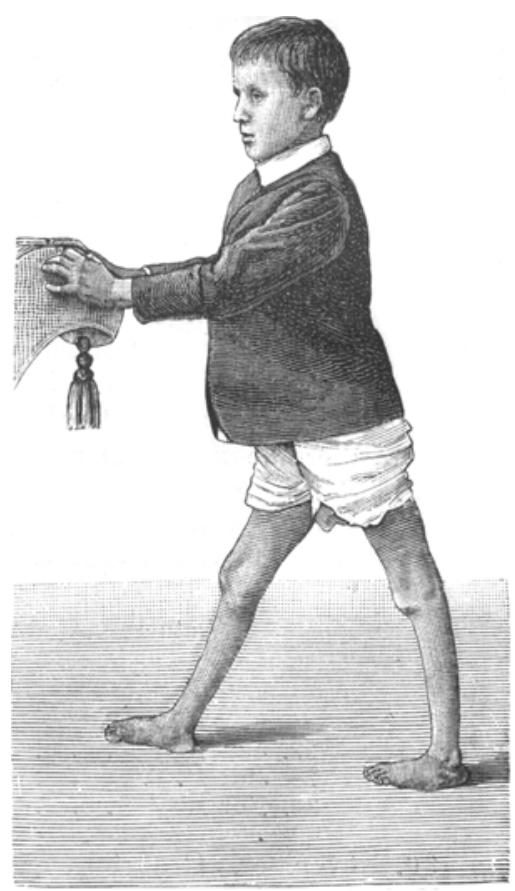

Erreichte Dorsalflexion. (Nach der photographischen Aufnahme.) 
rechts in 18 Monaten; dieselbe wurde durch die grosse Empfindlichkeit des Knaben verzögert.

Anfang Januar 1886. Maschinengypsverband seit Ende December 1885 weggelassen. Patient trägt während der Nacht und auch einige Stunden am Tage die mit Band und Schnalle zu befestigenden Fussmaschinen, deren richtige Wirkung er indessen durch Lösung der Schnallen vielfach vereitelt. Status Anfang April 1886. Die Form der Füsse ist jetzt normal. Adductions- und Supinationsverdrehung beseitigt. Die Fersen stehen senkrecht, was besonders hervorzuheben ist (Fig. 7 S. 199).

Dorsalflexion ist links bis zum Winkel von $80^{\circ}$, rechts von $85^{\circ} \mathrm{mög}$ lich (Fig. 8 S. 199). Bei dieser grösstmöglichen Dorsalflexion findet aber eine geringe Erhebung der Fersen und Spannung der Achillessehnen statt. Patient geht 1/4 Stunde Weges, jedoch nicht ohne Ermudung.

25. April 1886. Achillotenotomie, um Valgusstellung zu verhtiten.

\begin{tabular}{|c|c|c|c|c|c|c|}
\hline \multirow[t]{2}{*}{ Datum } & \multicolumn{3}{|c|}{$\begin{array}{c}\text { Rechter Fuss } \\
\text { Winkel }\end{array}$} & \multicolumn{3}{|c|}{$\begin{array}{c}\text { Linker Fuss } \\
\text { Winkel }\end{array}$} \\
\hline & I & II & III & I & II & III \\
\hline $\begin{array}{c}\text { 20. Juni } 1884 \\
\text { 3. August } \\
\text { 21. October } \\
\text { 3. December }\end{array}$ & $\begin{array}{l}\text { Grad } \\
\overline{116} \\
103\end{array}$ & $\begin{array}{l}\text { Grad } \\
\overline{-} \\
74 \\
78\end{array}$ & $\begin{array}{l}\text { Grad } \\
23 \\
18 \\
- \\
-\end{array}$ & $\begin{array}{l}\text { Grad } \\
\overline{-} \\
112 \\
102\end{array}$ & $\frac{\text { Grad }}{\overline{74}}$ & $\begin{array}{l}\text { Grad } \\
15 \\
12 \\
- \\
-\end{array}$ \\
\hline $\begin{array}{l}\text { 14. Januar 1885 } \\
\text { 23. Februar : } \\
\text { 27. April : : } \\
\text { 22. Juni : }: \\
\text { 20. August : } \\
\text { 12. October : } \\
\text { 18. März : }\end{array}$ & $\begin{array}{l}\overline{98} \\
\overline{95} \\
\overline{92} \\
87\end{array}$ & $\begin{array}{l}\overline{80} \\
\overline{85} \\
\overline{94} \\
94\end{array}$ & $\begin{array}{l}- \\
- \\
- \\
- \\
8 \\
8\end{array}$ & $\begin{array}{l}\frac{\overline{97}}{\overline{93}} \\
\frac{88}{83} \\
83\end{array}$ & $\begin{array}{l}80 \\
83 \\
89 \\
- \\
\overline{93} \\
92\end{array}$ & $\begin{array}{l}\overline{10} \\
\frac{\overline{0}}{\overline{0}}\end{array}$ \\
\hline
\end{tabular}

2. Johannes Bohn aus Eberstadt. Geboren 18. Angust 1876. Pes rarus sin. cong. 3. Grades.

Gypsverband bis zum Alter von 11/2 Jahren. Darauf Schienensehuh. Status am 25. Mai 1881 bei Beginn der Krauss'schen Behandlung: Linksseitiger Klumpfuss 3. Grades. Verkürzung der linken Extremität um $11 / 4 \mathrm{Cm}$., dieselbe ist abgemagert. Knie in Valgusstellung von $172^{0}$.

15. Juni. Durchschneidung der Fascia plant. 30. August. Achillotenotomie.

\begin{tabular}{|c|c|c|c|c|}
\hline \multirow{2}{*}{\multicolumn{2}{|c|}{ Datum }} & \multicolumn{3}{|c|}{$\begin{array}{c}\text { Linker Fuss } \\
\text { Winkel }\end{array}$} \\
\hline & & I & II & III \\
\hline $\begin{array}{l}\text { 22. Juli } 1881 \\
\text { 28. Juli } \text {. }^{\text {30. November }}\end{array}$ & . $:$ & $\begin{array}{c}\text { Grad } \\
110 \\
109 \\
80\end{array}$ & $\begin{array}{c}\text { Grad } \\
73 \\
76 \\
90\end{array}$ & $\begin{array}{c}\text { Grad } \\
18 \\
14 \\
0\end{array}$ \\
\hline
\end{tabular}

30. November. Gradstellung erreicht, also in 6 Monaten.

Ende December. Der Knabe fängt an mit Sehienenschuh zu gehen. Nachtmaschine. 
24. Mai 1882. Behandlung der Valgusstellung des Knies mit Schienengypsverband, mit dem der Knabe in die Schule geht.

\begin{tabular}{|c|c|}
\hline Kniekrümmung & $\begin{array}{l}\text { im Winkel } \\
\text { von Grad }\end{array}$ \\
\hline 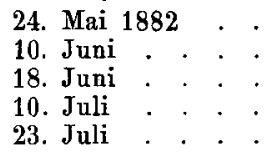 & $\begin{array}{l}172 \\
174 \\
176 \\
177 \\
178,5\end{array}$ \\
\hline
\end{tabular}

26. August 1883. Der Knabe geht $1 \frac{1}{2}$ Stunden Weges ohne viel Ermidung. Durch die Wirkung der Knieschiene wird der Fuss etwas mehr auf seinen äusseren Rand gestellt. - Das Tragen der Nachtmaschine wurde in letzter Zeit vernachlässigt, weshalb der Bogen des äusseren Fussrandes wieder mehr hervortritt.

24. November. Die Adduction wieder ausgeglichen. Wadenumfang rechts 22 , links $19 \mathrm{Cm}$.

24. März 1884. Die photographische Aufnahme von diesem Tage zeigt die vorhandene willkürliche Bewegungsfähigkeit. Patient legt 2 bis $21 / 2$ Stunden Weges ohne Ermüdung zurtick.

25. August. Der Knabe geht recht gut ohne Adduction.

Januar 1887. Obige Stellung von Fuss und Knie erhalten.

3. Joseph Nathan, Sohn von Sigmund Nathan aus Gaualgesheim, geboren 15. Juli 1881 .

Pes varus cong. duplex 2. Grades.

Im October 1881 begann die Behandlung.

Erster Arzt ordnete Anlegung von Flanellbinden und manuelles Redressement an. Die Mutter erlernte die Behandlung und setzte dieselbe zu Hause 6 Wochen lang ohne anscheinenden Erfolg fort.

Zweiter Arzt ordnete Schienen an, die 4 Wochen lang getragen wurden, angeblich ohne Erfolg.

Durch einen dritten Arzt wurden Redressementsversuche und Massage angeordnet, die bis zum Alter von 1//2 Jahren unter Gebrauch von Nachtmaschinen fortgesetzt wurden.

Durch einen vierten Arzt wurden Maschinen für die Nacht verordnet, die in Schuhen bestanden, welche durch Eisenstangen mit einem Hüftgürtel verbunden waren und mittelst Flanellbindén befestigt wurden. Angeblich blieben diese nicht liegen und war ein Erfolg nicht sichtbar.

Status am 21. Mai 1884 bei Beginn der Krauss'schen Behandlung: Rechts Pes varus cong. 1. und links 2. Grades.

Behandlung mit Maschinengypsverband begonnen.

19. Juni. Achillotenotomie beiderseits.

17. Juli. Rechts Winkel $\mathrm{I}=86^{\circ}$, links $=88^{\circ}$. Patient geht auf den Sohlen der Fiisse, den linken Fuss etwas nach einwärts stellend.

13. November. Gradrichtung erreicht, also in 5 Monaten. Der Knabe geht gut. Linker Fuss Neigung zu Valgusstellung, rechter Fuss mehr Festigkeit. Geht mit gewöhnlichen Schuhen den ganzen Tag herum. 
Kniee stark nach innen stehend, die noch behandelt werden sollen. Bekommt Schntirschuhe mit Schuheisen und Nachtmaschinen.

November 1885. Gewöhnliche Schuhe in Gebrauch gezogen. Nachtmaschine fortgebraucht. Valgusstellung der Kniee durch Knieschienen zu bekämpfen wird vergebens empfohlen.

October 1886. Richtung der Füsse erhalten. Knieschienengypsverband endlich in Anwendung gebracht.

Juni 1887. Valgusstellung der Kniee nahezu beseitigt. Gradstellung der Füsse erhalten.

4. Rudolf Henge aus Kriegsheim, geboren 6. Juni 1882.

Pes varus cong. duplex 2. Grades.

Anamnese Ende Juli 1882. Erster Arzt. Im Alter von 6 Wochen Gradrichtung in Narkose und Gypsverband. Alle 2-4 Wochen Verbandwechsel während 1/4 Jahr. Darauf Schienen mit Bindeneinwicklung.

Zweiter Arzt empfahl Fortsetzung der Behandlung, die Füsse würden wahrscheinlich ohne Sehnenschnitt gut werden. Fortsetzung bis September 1884, jedoch ohne weiteren Erfolg, als dass seit Anfang 1884 das Gehen auf äusserem Fussrand mit Schuheisen von Dröll, Mannheim, ermöglicht wurde.

October 1884. Status bei Beginn der Kraus s'schen Behandlung. Der Knabe geht beiderseits auf dem äusseren Fussrand. Rechts mässige Spannung der Achillessehne, links weniger, aber mehr Supinationsstellung, ohne dass weder Tibial. ant., noch Tibial. post. gespannt wären. Maschinengypsverband.

Februar 1885. Gradrichtung ziemlich hergestellt, also in 4 Monaten. Der Knabe geht auf flacher Sohle. Links Supination noch nicht ganz aufgehoben.

April. Weitere Besserung. Noch etwas Einwärtsstellung der Fussspitzen. Gehen mit Schuheisen gestattet. Nachtmaschinen angeordnet.

April 1886. Im Laufe des Jahres durch weniger sorgfältiges Anlegen der Nachtmasehinen Rückschritt in der Stellung und mehr Neigung, auf dem äusseren Fussrand zu gehen. Maschinengypsverband wieder angewandt.

15. Juli. Die Achillessehnen widersetzen sich der Vollendung der Gradrichtung und werden durchschnitten.

October. Anfang zu gehen mit Schuheisen. Mässige Einwärtsstellung der Fussspitzen. Fortgebrauch der Nachtmaschinen.

Juni 1887. Gradstellung nahezu erhalten. Zur Ueberwindung der Einwärtsstellung der Fussspitzen Verlängerung der Schuheisen bis zur Hüfte.

5. Wilhelm Reitz aus Bingen, geboren 11. November 1875.

Pes varus cong. dexter 2.-3. Grades.

A n am nese. Im Alter von 3 Monaten Achillotenotomie. Schienenschuh mit Flanellbinden. Recidiv infolge von Vernachlässigung. verbänden.

Mit 4 Jahren Gradrichtung in Narkose upd Behandlung mit Gyps-

3. Mai 1884. Status bei Beginn der Behandlung von Dr. Krauss. Ziemlich straffe Bänder. Geringe Beweglichkeit, viel Widerstand bei Versuch der Gradrichtung. 
12. Mai. Durchschneidung der Fascia plantaris.

11. Juli. Achillotenotomie.

8. August. Durchschneidung des Tibial. post. Wadenumfang rechts 21,5 , links $25,5 \mathrm{Cm}$.

October. Gradrichtung bewirkt, also in 5 Monaten.

November. Anfang mit Schuheisen zu gehen. Nachtmaschine verordnet.

Mai 1885. Der Knabe geht sehr gut, kann selbst 1 Stunde Weges ohne Ermudung zuriicklegen.

December. Durch Frostbeulen Vernachlässigung der Maschinenbehandlung und Rückschritt in der Stellung. Geschwürsbildung, namentlich über dem äusseren Knöchel.

Mai 1886. Rückschritt theil weise durch Maschinenbehandlung wieder aufgehoben.

März 1887. Geht zwar flach auf der Sohle, jedoch ist die Ueberwindung der Supinationsstellung nicht so vollständig, wie dieselbe nach der ersten Behandlung im November 1884 gewesen war, wozu die Wiederkehr der Frostbeulen und das Widerstreben gegen Nachtmaschinen beiträgt.

Fortgebrauch der Schuheisen und Nachtmaschinen.

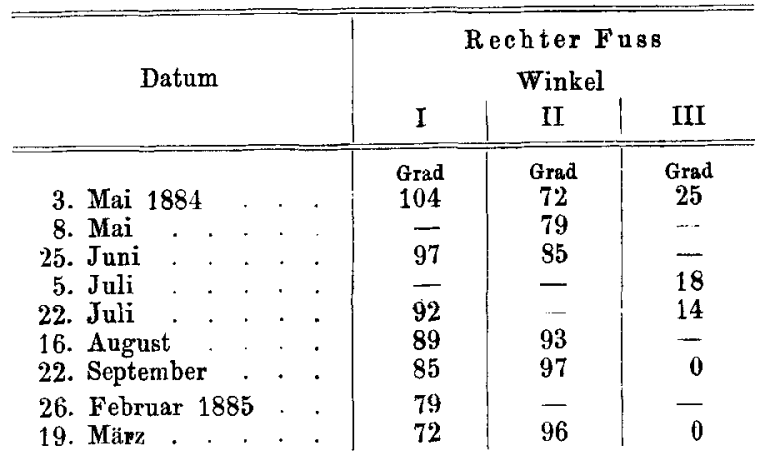

6. Philipp Poh aus Freilaubersheim, geboren 23. Sept. 1876.

Pes varus cong. duplex 2. Grades.

A n am nese. Patient hat eine jüngere Stiefschwester mit Pes varus cong. dexter.

Juni 1877. Anfang der Behandlung. Erster Arzt: Gypsverbände, die alle 14 Tage erneuert wurden. Nach 8 Wochen Besserung. Beiderseitige Achillotenotomie. Schienenschuhe von Dröll, Mannheim. Die Sohlen konnten aber nicht flach auf den Boden aufgesetzt werden.

October 1879. Z weiter Arzt: Schienenschuhe aus Bonn, die nach 3 Wochen zerbrachen. Erneuerung der Schienenschuhe durch den Freilaubersheimer Schlosser.

October 1882. Dritter Arzt: Achillotenotomie und Redressement forcé in Narkose. Anlegung von Schienen mit Heftpflaster, darauf Gypsverbände und zuletzt Wasserglasverband. 6 Monate später hintere Hohlschiene von Holz mit einem durch Scharnier an die Hoblschiene befestigten Fussbrett. Dieser Apparat wurde ca. 1/2 Jahr getragen. 
26. November 1883. Beginn der Behandlung von Dr. Krauss. Status: Kräftiger Knabe, 7 Jahre alt. Beide Füsse mit allen Merkmalen von Pes varus mittleren Grades; wenig bewegliche Gelenke. Beim Versuch der Gradrichtung spannt sich besonders die Fascia plant., links in hohem Grade. Achillessehne mässig gespannt. Maschinengypsverband.

16. December. Besserung, auch durch die Winkelmessung nachweisbar. Durchschneidung der Fascia plant. beiderseits.

20. Januar 1884. Weitere Besserung. Spannung der Sehnen des M. tibial. post. beim Versuch der Gradrichtung, Durchschneidung beiderseits.

9. Februar. Der vor Durchschneidung der Sehnen des M. tibial. post. bei Gradrichtung durch Muskelcontraction sich geltend machende Widerstand ist geschwunden. Formverbesserung wahrnehmbar, die sich aber weniger in den Winkelmaassen geltend macht.

1. März. Entschiedene Besserung in der Form. Stehen auf flacher Sohle macht weniger Beschwerden. Durchschneidung der Sehnen des M. flexor digit. ped. brevis am Ursprung am Tuber calcanei.

26. April. Zweite Durchschneidung der Fascia plant. beiderseits im vorderen Drittel der Fusssohle.

8. November. Der Knabe geht ziemlich gut auf den Sohlen beider Füsse. Linke Ferse zeigt immer noch Supination, rechte zeigt dieselbe in geringerem Grade. - Gradrichtung erreicht: rechts in 7, links in 12 Monaten. Fortsetzung des Maschinengypsverbandes. Plantarflexion beschränkt (Folge der längeren Dauer des Verbandes).

März 1885. Nachbehandlung, bestehend in richtiger Anlegung der Nachtmaschinen, nicht in genijgender Weise fortgesetzt, deshalb etwas Rtickschritt bemerkbar.

Juli. Besserung.

April 1886. Geht gut mehrere Stunden des Tages, doch ist noch schwache Supinationsdrehung der linken Ferse vorhanden.

3. Juli 1887. Orthopädische Nachbehandlung in der letzten Zeit nicht mit der gehörigen Sorgfalt betrieben. Nachtmaschinen nicht beständig getragen. Supinationsstellung links und rechts in Stellung des Calcaneus vermehrt. Der Gang ist dementsprechend auch mehr stossweise und weniger mit elastischer Bewegung des Fussgelenks. Gespannt sind M. tibial. ant. und Achillessehne, deren Durchschneidung in Aussicht genommen wird.

\begin{tabular}{|c|c|c|c|c|c|c|}
\hline \multirow[t]{2}{*}{ Datum } & \multicolumn{3}{|c|}{$\begin{array}{c}\text { Rechter Fuss } \\
\text { Winkel }\end{array}$} & \multicolumn{3}{|c|}{$\begin{array}{c}\text { Linker Fuss } \\
\text { Winkel }\end{array}$} \\
\hline & I & II & III & $\mathrm{I}$ & II & III \\
\hline 26. November 1883 & $\begin{array}{l}\text { Grad } \\
100\end{array}$ & $\begin{array}{c}\text { Grad } \\
78\end{array}$ & $\begin{array}{c}\text { Grad } \\
12\end{array}$ & $\begin{array}{l}\text { Grad } \\
106\end{array}$ & $\begin{array}{c}\text { Grad } \\
80\end{array}$ & $\begin{array}{c}\text { Grad } \\
14\end{array}$ \\
\hline $\begin{array}{l}\text { 19. Januar } 1884 \\
\text { 26. April } .\end{array}$ & $\begin{array}{l}97 \\
93\end{array}$ & $\begin{array}{l}81 \\
86\end{array}$ & $\begin{array}{r}12 \\
9\end{array}$ & $\begin{array}{r}100 \\
95\end{array}$ & $\overline{86}$ & $\begin{array}{r}14 \\
8\end{array}$ \\
\hline 5. Juli : : & - & 88 & 6 & - & 92 & $\mathbf{3}$ \\
\hline 9. August . & 88 & - & - & 87 & - & - \\
\hline 8. November . & 85 & 92 & - & 81 & - & - \\
\hline 3. Januar 1885 & 80 & 91 & 6 & 76 & 90 & 2 \\
\hline
\end{tabular}


7. Isidor Pla ut aus Darmstadt, geboren 8. März 1883.

Pes varus sin. cong. 2.-3. Grades.

Onkel mitterlicherseits hatte Pes varus cong. duplex.

20. April 1883. Status bei Beginn der Krauss'schen Behandlung. Feingebildetes Kind. Achillessehne stark gespannt. Maschinengypsverband. Erneuerung alle 6-8 Tage.

1. Juni. Entschiedene Besserung in allen Krummungsrichtungen.

1. August. Normalstellung des Fusses soweit erreicht, dass der Fuss ohne Verband nur wenig Neigung zur Rückkehr in die Varusstellung zeigt. Dies veranschaulicht die photographische Aufnahme. Gradrichtung also in $3 \frac{1}{2}$ Monaten.

October. Der Verband wird mit Unterbrechung weggelassen; je 2 Tage und 1 Nacht ohne Verband, dann 2 Nächte und 1 Tag mit Verband.

December. Schuh mit Seitenstange am Tage, Nachts Maschinchen mit Band und Schnalle.

Februar 1884. Anfang zu gehen.

März 1885. Geringer Grad von Crus varum mit Neigung zu Genu valgum rechts und links.

December. Anwendung der Nachtmaschinen wurde fortgesetzt. Im Gehen nur geringe Adduction der Fussspitzen.

4. September 1886. Schienengypsverband gegen beiderseitiges Genu valgum bei gleichzeitigem Fortgebrauch der Fussnachtmaschinen.

15. März 1887. Genu valgum beiderseits beseitigt. Gradstellung des linken Fusses erhalten, jedoch eine leichte Verkürzung der Wadenmusculatur.

10. Juni. Status wie am 15. März. Achillotenotomie in Aussicht genommen.

8. Georg Hasenzah1 aus Biebesheim, geboren 29. April 1869.

Pes varo-equinus dexter 2. Grades
Genu contractum

Anamnese. Im Alter von $3 / 4$ Jahr Scharlach. 14 Tage später bemerkte die Mutter, dass das Kind Arm und Bein der rechten Seite schlaff herabhängen liess. Aufnahme in einem Spital während 7 Monaten, w oselbst Elektricität ohne Erfolg angewandt wurde. Im Alter von 3 Jahren erneute elektrische Behandlung, ebenfalls ohne Erfolg.

Mit 5 Jahren begann Patient mit Hülfe eines Stockes mit krummen Knieen mühsam zu gehen. Die rechte Ferse wurde immer mehr und mehr in die Höhe gezogen. Das Gehen ging immer schlechter bis gegen Juli 1884.

1. Juli 1884. Status bei Beginn der Krauss'schen Behandlung. Gut entwickelter Knabe. Es findet sich eine Lähmung des rechten Armes und Beines. Rechte Hand in Bengestellung. Bewegungsfähigkeit der Gelenke von Schulter, Ellenbogen und Hand rechts beschränkt, ebenso von rechtem Hiuft-, Knie- und Fussgelenk. Rechtes Fussgelenk so hochgradig plantarflectirt, dass die Rulckfläche der Zehen beim Stehen und Gehen sich gegen den Fussrücken anlegt. Dabei ein leichter Ueber- 
gang zur Varusstellung. Gespannt ist beim Versuch der Gradrichtung nur die Achillessehne.

Rechts Achillotenotomie und Maschinengypsverband.

6. August. Maschinengypsverband durch Maschine mit Band und Schnalle ersetzt.

Ende September. Gradrichtung erreicht, also in $2^{1 / 2}$ Monaten.

28. October. Durchschneidung der Sehne des Semimembranosus, Semitendinosus und Biceps und der an einer Stelle in der Kniekehle gespannten Fascia lata. Anlegung einer Kniegelenksschiene.

30. November. Knie in grader Stellung.

10. December. Fängt an zu gehen.

Anfang Februar 1885. Geht mit Hülfe eines Stockes kleinere Wegstrecken.

\begin{tabular}{|c|c|c|}
\hline Datum & & $\begin{array}{c}\text { Rechter Fuss } \\
\text { I. Winkel }\end{array}$ \\
\hline $\begin{array}{l}\text { 10. Juli } 1884 \\
\text { 25. Juli } \\
\text { 15. August } \\
\text { 28. August } \\
\text { 5. September }\end{array}$ & 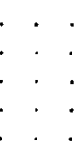 & $\begin{array}{r}150^{\circ} \\
133^{\circ} \\
110^{\circ} \\
91^{\circ} \\
84^{\circ}\end{array}$ \\
\hline
\end{tabular}

9. Bertha Wolff aus Hochstetten, geboren 2. September 1880 .

Pes varus cong. uterque 2. Grades.

Erster Arzt. Behandlung mit Gypsverband gleich nach der Geburt.

$\mathrm{Z}$ weiter Arzt. Durchschnitt 1883 die Achillessehne ohne besonderen Erfolg.

2. Juni 1886. Anfang der Krauss'schen Behandlung. Statts : $53 / 4$ Jahre altes, ziemlich zartes, aber gesundes Mädchen. Rechter Fuss

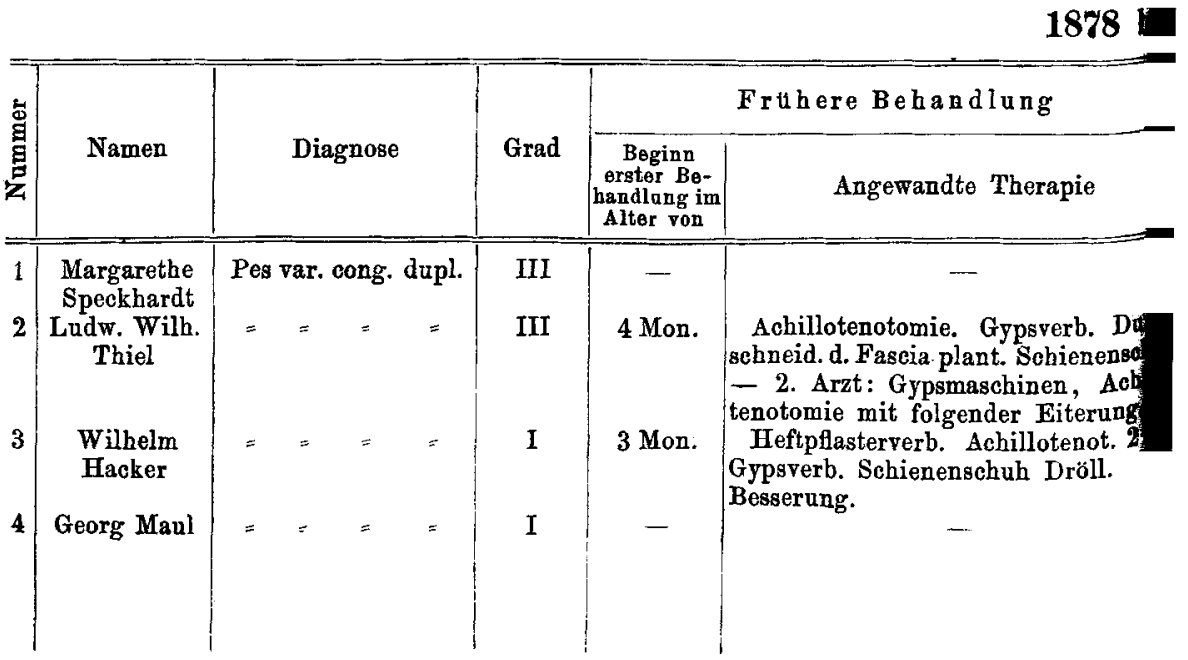


zeigt hochgradigeren Varus. Gespannt Fascia plant. rechts beim Versuch der Gradrichtung. Mässig gespannt beide Achillessehnen.

15. Juni. Durchschneidung der Fascia plaut. rechts.

15. Juli. Achillotenotomie beiderseits.

Anfang October. Gradrichtung erreicht, also in 4 Monaten. Die rechte Ferse zeigt noch geringe Supination.

15. December. Anfang mit Schuheisen zu gehen. Nachtmaschinen.

März 1887. Linker Fuss zeigt Neigung zu Valgusstellung, Ferse rechts hartnäckig in leichter Supination verharrend.

22. Juli. Das Kind geht mit den Schienenschuhen iuber $1 / 2$ Stunde Weges ohne Ermïdung. Gang verhältnissmässig gut mit sehr wenig Adductionsneigung; Supinationsstellung der rechten Ferse gleichwohl noch nicht ganz beseitigt. Achillotenotomie rechts in Aussicht genommen, eventuell, wenn nöthig, auch Durchschneidung des Tibial. post. Wadenumfang rechts und links $=18,5 \mathrm{Cm}$.

\begin{tabular}{|c|c|c|c|c|c|c|c|c|}
\hline \multirow{2}{*}{ Datum } & \multicolumn{4}{|c|}{$\begin{array}{c}\text { Rechter Fuss } \\
\text { Winkel }\end{array}$} & \multicolumn{4}{|c|}{$\begin{array}{c}\text { Linker Fuss } \\
\text { Winkel }\end{array}$} \\
\hline & I & $\begin{array}{l}\text { Excursion } \\
I\end{array}$ & II & III & I & $\begin{array}{c}\text { Excursion } \\
\text { I }\end{array}$ & II & III \\
\hline $\begin{array}{l}\text { 27. Juli } 1886 \\
\text { 11. August } \\
\text { 13. September }\end{array}$ & $\begin{array}{r}\text { Grad } \\
108 \\
102 \\
82\end{array}$ & $\begin{array}{c}\text { Grad } \\
- \\
- \\
-\end{array}$ & $\begin{array}{c}\text { Grad } \\
78 \\
78 \\
87\end{array}$ & $\begin{array}{c}\text { Grad } \\
30 \\
-\end{array}$ & $\begin{array}{r}\text { Grad } \\
103 \\
101 \\
82\end{array}$ & $\frac{\text { Grad }}{-}$ & $\begin{array}{c}\text { Grad } \\
81 \\
84 \\
86\end{array}$ & $\begin{array}{c}\mathrm{Grad} \\
21 \\
-\end{array}$ \\
\hline $\begin{array}{l}\text { 21. Februar } 1887 \\
\text { 22. Juli } .\end{array}$ & $\begin{array}{l}76 \\
76\end{array}$ & $\begin{array}{c}76-115 \\
\text { also } 39 \text { Exc. }\end{array}$ & $\overline{94}$ & $\overline{6}$ & $\begin{array}{l}74 \\
74\end{array}$ & $\begin{array}{c}74-115 \\
\text { also } 41 \text { Exc. }\end{array}$ & $\begin{array}{l}90 \\
90\end{array}$ & $\begin{array}{l}7 \\
0\end{array}$ \\
\hline
\end{tabular}

In der folgenden Tabelle sind die gesammten vom Jahre 1878 bis Mitte 1887 behandelten Fälle von Pes varus, deren Vorgeschichte, Behandlungsweise und Heilerfolg zusammengestellt.

38.

\begin{tabular}{|c|c|c|c|c|}
\hline \multicolumn{5}{|c|}{ Behandlung von Dr. med. Krauss in Darmstadt } \\
\hline $\begin{array}{l}\text { in der } \\
\text { ding } \\
\text { ier von }\end{array}$ & $\begin{array}{l}\text { Dauer der Be- } \\
\text { handlung bis zur } \\
\text { Gradrichtung }\end{array}$ & $\begin{array}{c}\text { Angewandte Therapie ausser dem } \\
\text { Masehinengypsverband }\end{array}$ & $\begin{array}{l}\text { Noch in } \\
\text { Behand- } \\
\text { lung }\end{array}$ & Heilresultat \\
\hline & 4 Monate & $\begin{array}{l}\text { Ohne Sehnendurehsehneidung. Achil- } \\
\text { lotenot. nöthig, aber bisher verweigert. }\end{array}$ & $\begin{array}{l}\text { in Beob- } \\
\text { achtung }\end{array}$ & geheilt \\
\hline & 8 Monate & $\begin{array}{l}\text { Tenot. d. Fascia plant. u. Tibial. post. } \\
\text { beiderseits, Abductor hall., Flexor bre- } \\
\text { vis digit. pedis. }\end{array}$ & in Beob. & geheilt \\
\hline $3 \mathrm{M}$ & $3^{1 / 2}$ Monate & $\begin{array}{l}\text { Tenot. von Fascia plant. dext., Achil- } \\
\text { lotenotomie beiderseits. - An Diphthe- } \\
\text { ritis gestorben. }\end{array}$ & nein & geheilt \\
\hline ion. & 4 Monate & $\begin{array}{l}\text { Durchschneidg. beider Achillessehnen } \\
\text { wegen Valgus stellung. Nachträg- } \\
\text { lich bildete sich Valgussteliung aus, die } \\
\text { durch die Achillotenot. beseitigt wurde. } \\
\text { (Neue Methode von Dr. Krauss.) }\end{array}$ & in Beob. & geheilt \\
\hline
\end{tabular}




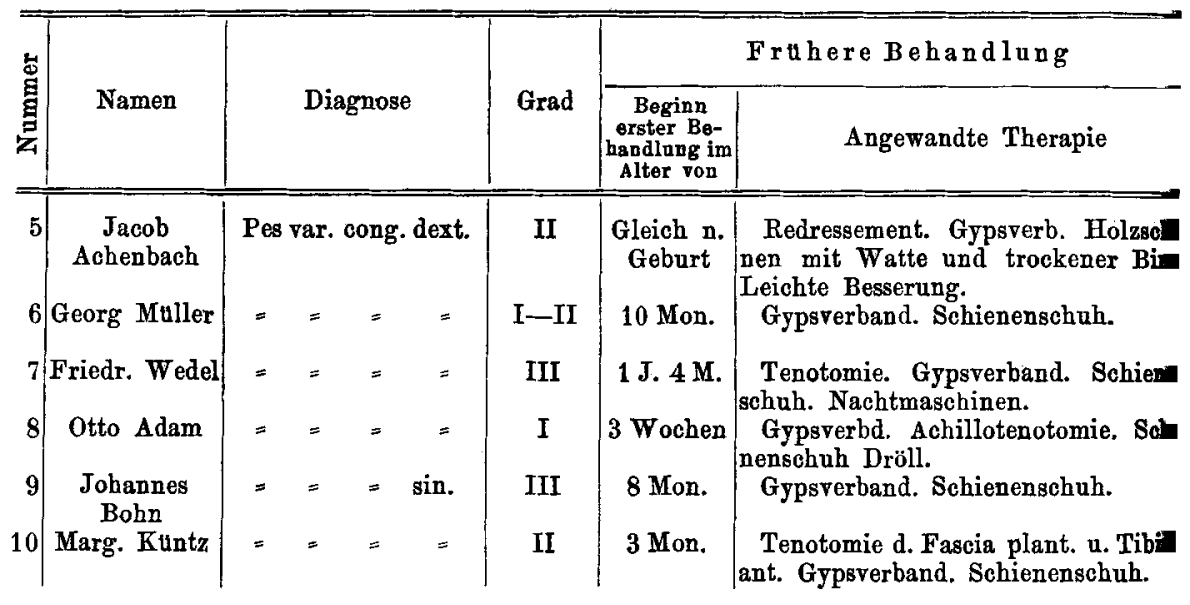

\section{3}

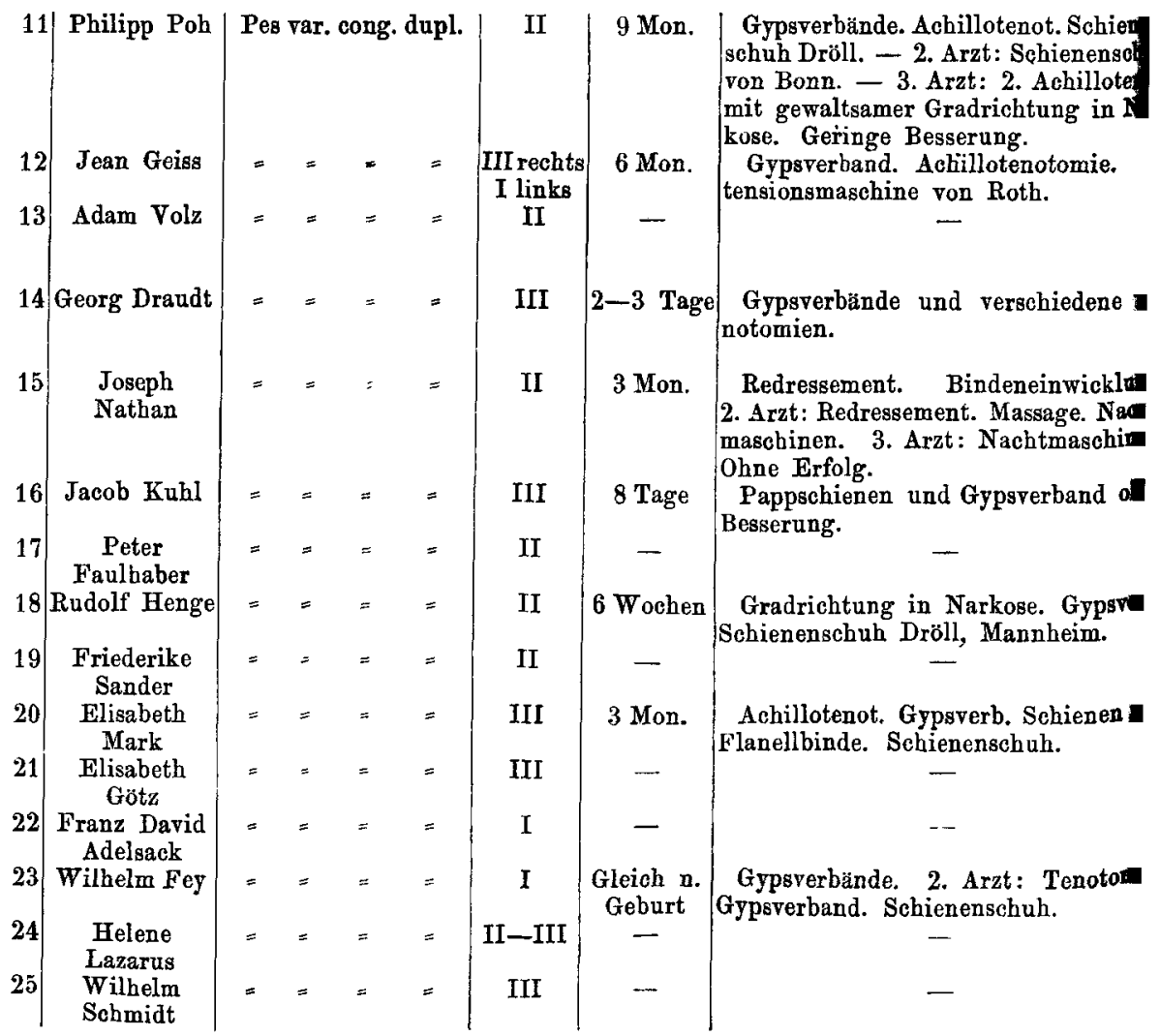


Behandlung von Dr. med. Krauss in Darmstadt

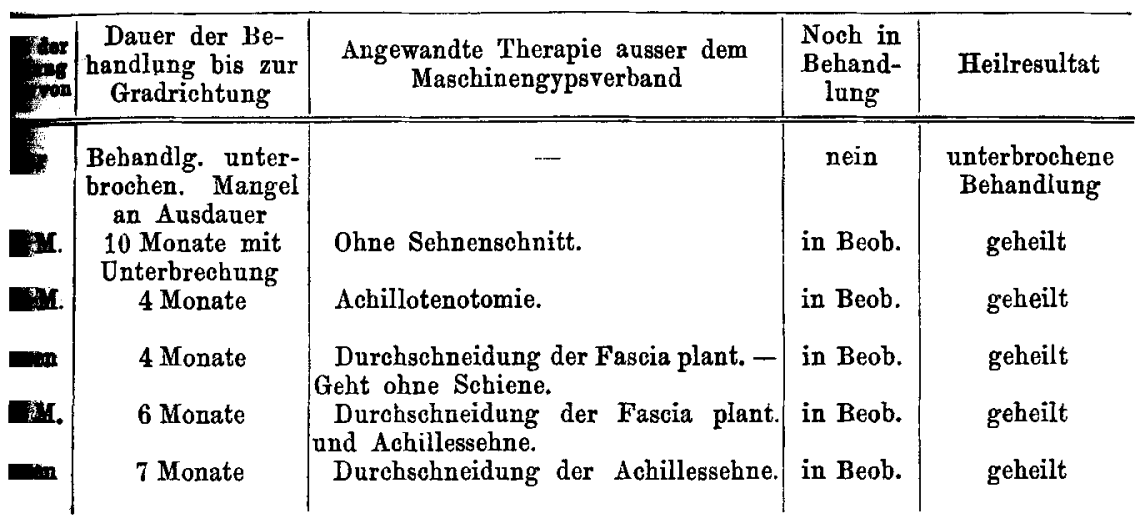

\section{$188 \%$.}

ren | rechts 7 Monate, links 12 Monate

ax. 9 Mon. mit Unterbrechg. durch Pat. 11 M. mit Unterbrechung durch Pat. links 12 Monate, rechts 18 Monate

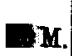

\section{Monate}

Tonate

a.
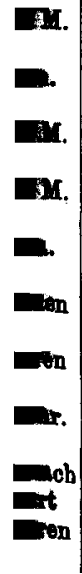

\section{Monate}

5 Monate

4 Monate

2 Monate

4 Monate

5 Monate

Supination uber-

wunden

3 Monate

5 Monate

4 Monate
Durchschneidung d. Faseia plant. bei- in Beob. derseits 2 mal, des Tibial. post., Flexor digit. ped. brevis.

Achillotenotomie beiderseits. - Unterbrechung der Behandlung.

Achillotenot. rechts. - Nachbehandl. vernachlässigt. Aehillotenotom. nöthig. Mehrfache Unterbrechung der Behandl. Durchschneidung d. Fascia plant. beiderseits 2 mal, des Abductor hall. beiderseits, Tibial. ant. beiderseits. Achillotenotomie beiderseits.

Achillotenotomie beiderseits.

Achillotenotomie beiderseits.

Achillotenotomie beiderseits.

Achillotenotomie beiderseits.

Achillotenotomie.

Ohne Sehnenschnitt.

Durchschneidung der Fascia plant. und Achillessehne.

Ohne Achillotenotomie.

Durehschneidung der Fascia plant. in und des Lig. tibio-navic. nahezu vollständig geh. Mangelnde Ausdauer in Nachbehandlung

nicht ja

nicht unvollständig geheilt geheilt

geheilt

in Beob. geheilt

nicht geheilt

in Beob. geheilt

in Beob. geheilt ja ja

geheilt gebessert geheilt gebessert geheilt geheilt geheilt 


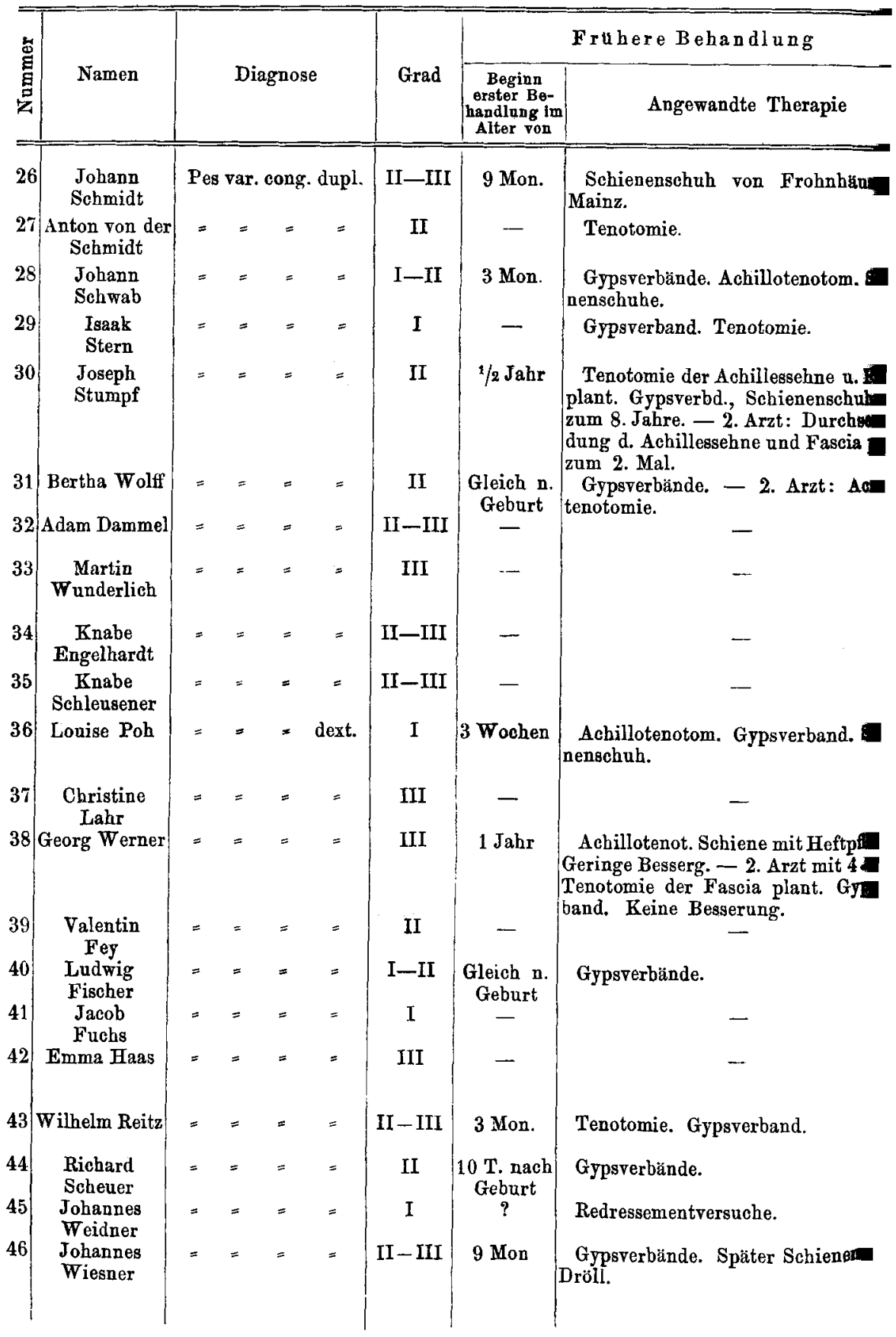


Behandlung ron Dr. med. Krauss in Darmstadt

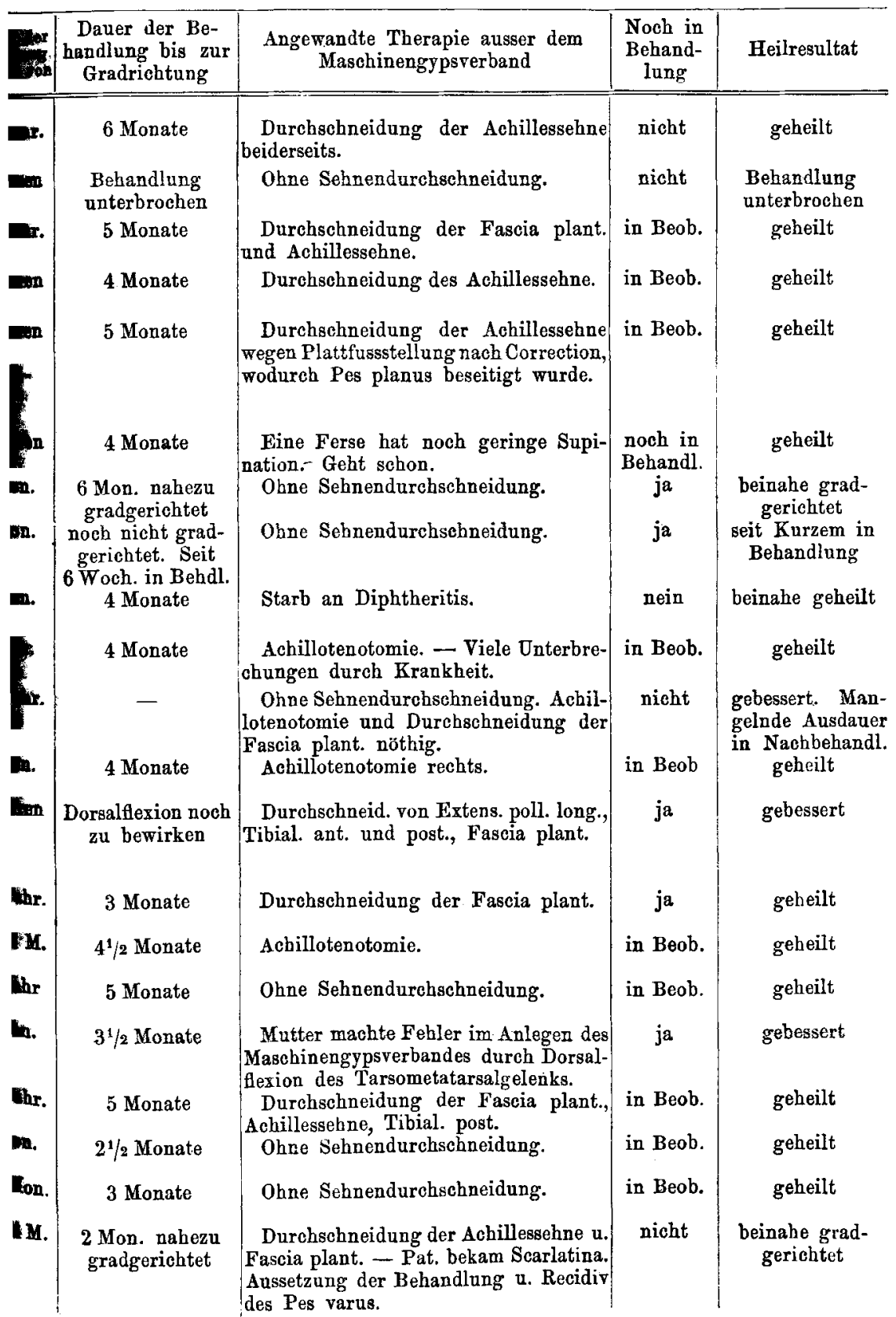




\begin{tabular}{|c|c|c|c|c|c|}
\hline \multirow{2}{*}{ 总 } & \multirow[b]{2}{*}{ Namen } & \multirow[b]{2}{*}{ Diagnose } & \multirow[b]{2}{*}{ Grad } & \multicolumn{2}{|r|}{ Fruhere Behandlung } \\
\hline & & & & $\begin{array}{c}\text { Beginn } \\
\text { erster Be- } \\
\text { handlong im } \\
\text { Alter vou }\end{array}$ & Angewandte 'Therapie \\
\hline 47 & $\begin{array}{l}\text { Ludwig } \\
\text { Fuchs }\end{array}$ & Pes var. cong. sin. & III & - & - \\
\hline 48 & Isidor Plaut & Pes var. cong. sin. & II-III & - & - \\
\hline 49 & $\begin{array}{l}\text { Katharina } \\
\text { Hofmann }\end{array}$ & Pes var. cong. sin. & I & 6 Mon. & Schiene mit Kleisterverband. \\
\hline 50 & $\begin{array}{l}\text { Dorothea } \\
\text { Beikler }\end{array}$ & Pes var. cong. sin. & III & $1 / 2 \mathrm{Jahr}$ & Tenotomie. Sohienenschuh. \\
\hline 51 & $\begin{array}{l}\text { Katharina } \\
\text { Hensel }\end{array}$ & $\begin{array}{l}\text { Pes var. cong. sin. } \\
\text { Pes valg. cong. dext. }\end{array}$ & III & - & - \\
\hline 52 & Ladwig Rohde & Pes var. cong. sin. & II-III & - & - \\
\hline 53 & $\begin{array}{c}\text { Gustar } \\
\text { Oppenheimer }\end{array}$ & $\begin{array}{l}\text { Pes equino-var. sin. } \\
\text { traumat. durch Quet- } \\
\text { sehung d. Fusswurzel. }\end{array}$ & II & - & $\begin{array}{l}\text { Gypsverband. Achillotenot. Soht } \\
\text { Schuheisen. }\end{array}$ \\
\hline 54 & Maria & Pes var. paral. dext. & I & 一 & - \\
\hline 55 & $\begin{array}{l}\text { Formhals } \\
\text { Georg } \\
\text { Hasenzahl }\end{array}$ & $\begin{array}{l}\text { Pes varo - eq. paral. } \\
\text { dext. Genu contrac- } \\
\text { tum e paralysi. }\end{array}$ & II & $\begin{array}{l}1 \mathrm{~J} .1 \mathrm{M} . \mathrm{n} . \\
\text { Lähmung }\end{array}$ & Elektricität mehrmals ohne Er \\
\hline 56 & Anna Weiss & Pes var. paral. dext. & II & $\begin{array}{l}5 \text { J. nach } \\
\text { Lähmung }\end{array}$ & $\begin{array}{l}\text { Achillotenotomie ohne gleich } \\
\text { Anlegung eines Verbandes. }\end{array}$ \\
\hline 57 & $\begin{array}{l}\text { Maria Anna } \\
\text { Becker }\end{array}$ & Pes var. paral. dext. & II & $\begin{array}{l}\text { Bald nach } \\
\text { Lähmung }\end{array}$ & $\begin{array}{l}\text { Gypsverband. }-2 . \text { Arzt: Teno } \\
\text { u. Gypsvbde. Kurzdauernde Bess }\end{array}$ \\
\hline 58 & $\begin{array}{l}\text { Magdalene } \\
\text { Strohmenger }\end{array}$ & Pes var. paral, dext. & II-III & - & $\begin{array}{l}\text { Keine Behandlung vorher. Sch } \\
\text { schuh im 12. Jahre. Verheirath. 18 } \\
\text { 32. Jahre. - Der zuletzt behand } \\
\text { Chirurg erklärt Amput. pedis fur n } \\
\text { welche Pat. ablehnt. Gehen seit } \\
\text { dureh Sohmerzen im rechten Fus } \\
\text { erträglich. Gebraucht Krucken. }\end{array}$ \\
\hline 59 & Knabe Reis & $\begin{array}{l}\text { Pes equino-var. pa- } \\
\text { ralyt. dext. }\end{array}$ & II & - & - \\
\hline 60 & $\begin{array}{l}\text { Mädchen } \\
\text { Bendheim }\end{array}$ & $\begin{array}{l}\text { Pes var. paral. sin. } \\
\text { Kinderlähm. auf Knie } \\
\text { sich erstreckend. }\end{array}$ & II & - & 1 \\
\hline 61 & Ida Löb & Pes var. paral. sin. & I & $\begin{array}{l}\text { Bald nach } \\
\text { Lähmung }\end{array}$ & $\begin{array}{l}\text { 1. Arzt àsserte sich dahin, } \\
\text { nichts zu machen. 2. Arzt ent } \\
\text { Schuheisen. - Status quo ante. }\end{array}$ \\
\hline 62 & Jacob Strub & $\begin{array}{l}\text { Pes eq.-var. par. sin. } \\
\text { Genu contract. eparal. }\end{array}$ & II & - & - \\
\hline 63 & $\begin{array}{l}\text { Mädchen } \\
\text { Braun }\end{array}$ & Pes eq.-var. par. sin. & I & - & - \\
\hline 64 & $\begin{array}{l}\text { Mädchen } \\
\text { Hörrr }\end{array}$ & Pes eq.-var. par. sin. & II-III & - & - \\
\hline
\end{tabular}

Wir schliessen hieran in einer zweiten Tabelle, die sich auf 16 Zwecke des Vergleiches aufgenommenen Winkelmessungen. 
Behandlung ron Dr. med. Krauss in Darmstadt.

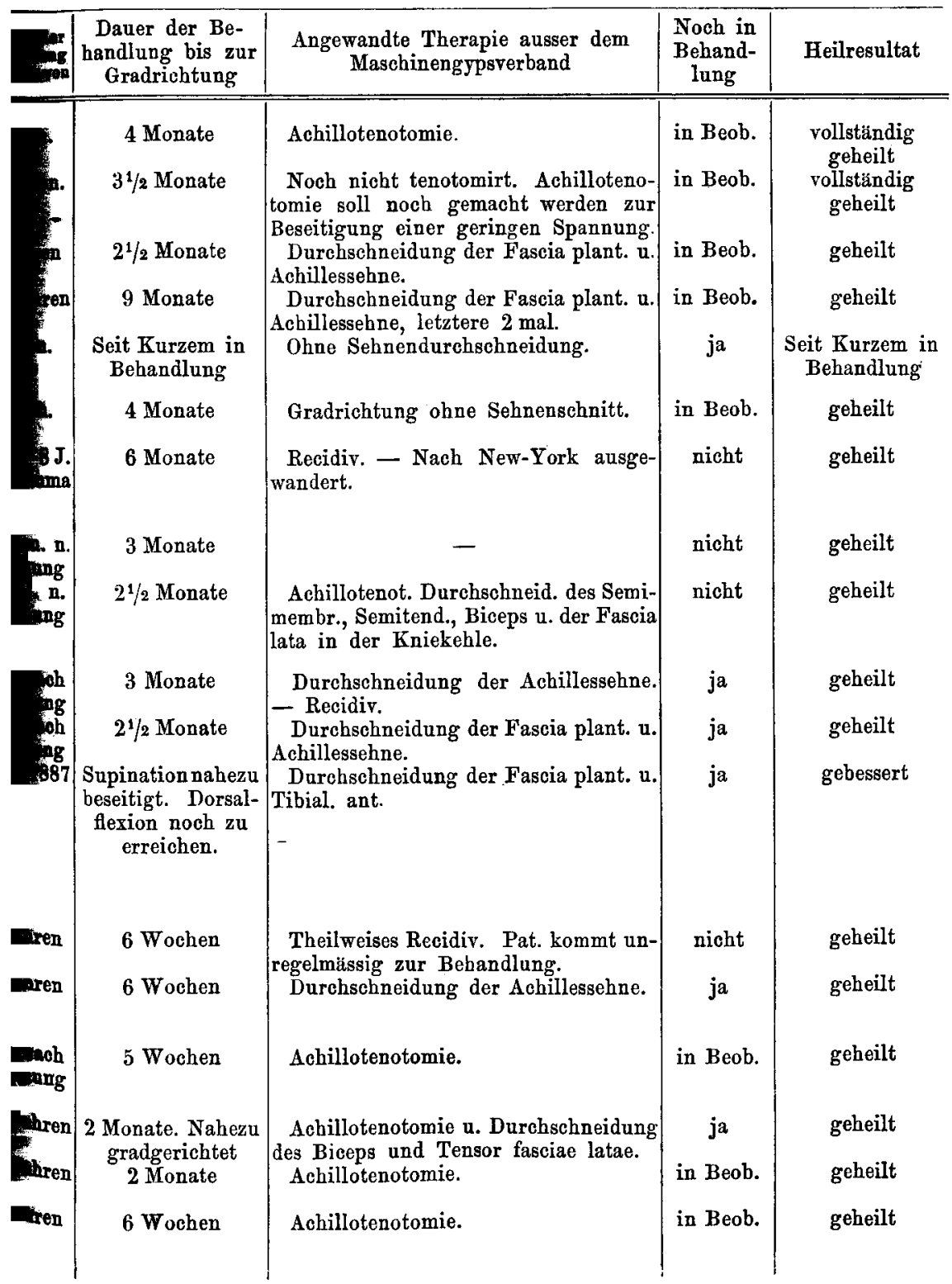

Fälle bezieht, die bei Beginn und am Ende der Behandlung zum 


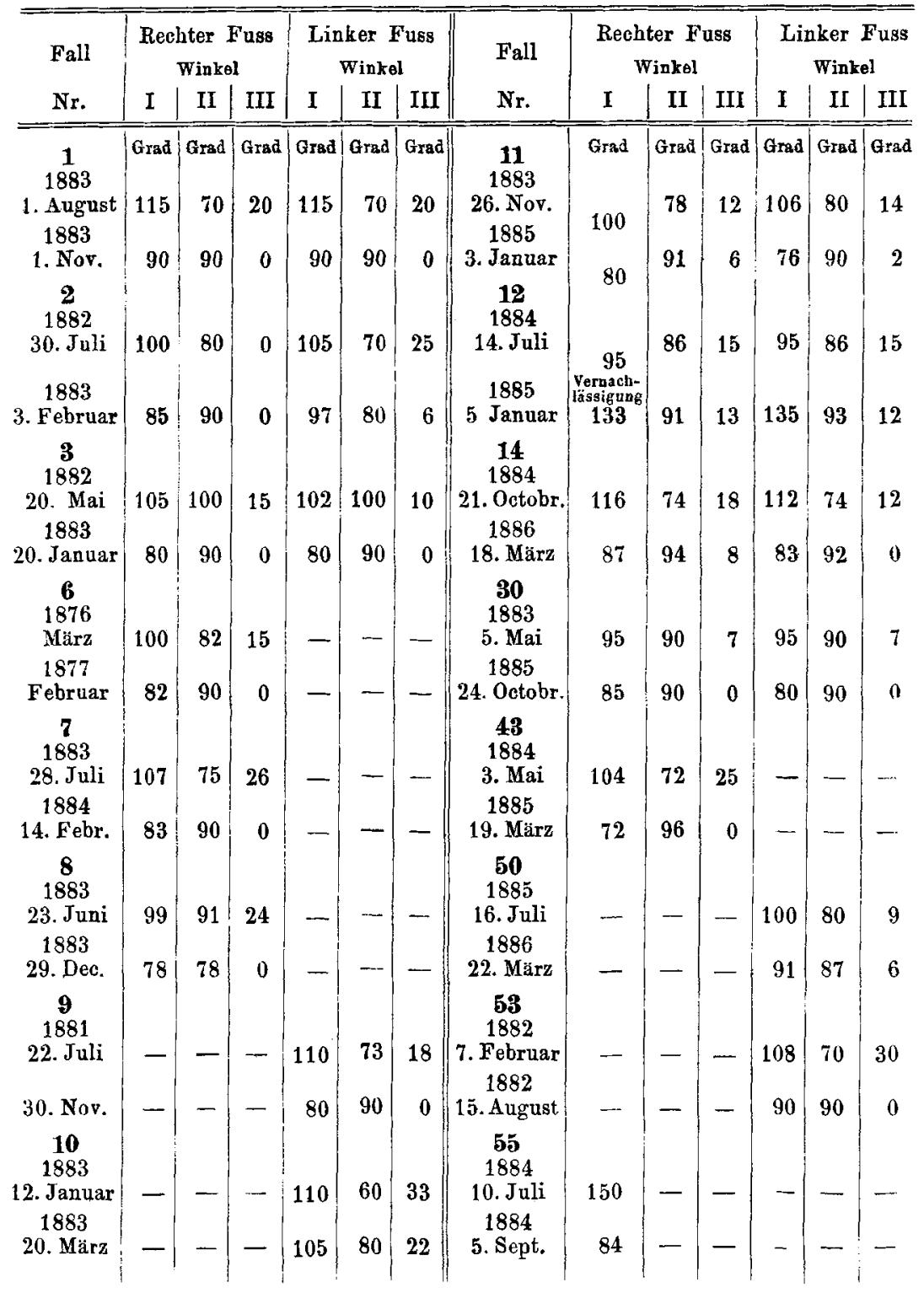

Wenn wir uns nun, um uns einen Ueberblick ïber die von Dr. Krauss behandelten Fälle von Pes varus und über das gesammte Heilresultat zu verschaffen, eine Zusammenstellung machen, so ergiebt sich Folgendes: 


\begin{tabular}{|c|c|c|c|c|c|c|c|c|c|c|c|c|}
\hline $\begin{array}{c}\text { Behandelt wurden } \\
\text { von }\end{array}$ & $\begin{array}{l}\text { Pes } \\
\text { varus } \\
\text { Fälle }\end{array}$ & I & $\begin{array}{r}\text { Co } \\
|I-I I|\end{array}$ & $\begin{array}{r}\text { ngen } \\
\text { Gra } \\
\text { II } \mid\end{array}$ & $\begin{array}{l}\text { aitale } \\
\text { III-III }\end{array}$ & III & I & $|\mathrm{I}-\mathrm{II}|$ & $\begin{array}{l}\text { raly } \\
\text { Gro } \\
\text { II }\end{array}$ & $\begin{array}{l}\text { tische } \\
|\mathrm{II}-\mathrm{III}|\end{array}$ & III & $\mid \begin{array}{c}\text { Tran- } \\
\text { ma- } \\
\text { tische } \\
\text { Grad II }\end{array}$ \\
\hline \multirow[t]{2}{*}{$\begin{array}{l}1878-1883 \\
1883 \text { bis Mitte } 1887\end{array}$} & $\begin{array}{l}10 \\
54\end{array}$ & $\begin{array}{l}3 \\
7\end{array}$ & $\begin{array}{l}1 \\
2\end{array}$ & $\begin{array}{r}2 \\
11\end{array}$ & $\overrightarrow{9}$ & $\begin{array}{r}4 \\
13\end{array}$ & $\overline{3}$ & $\overline{-}$ & $\overline{6}$ & $\overline{2}$ & - & $\overline{1}$ \\
\hline & 64 & 10 & 3 & 13 & 9 & 17 & 3 & -1 & 6 & 2 & -1 & 1 \\
\hline
\end{tabular}

\begin{tabular}{|c|c|c|c|c|c|c|c|}
\hline \multirow[b]{2}{*}{$\begin{array}{c}\text { Hierron kommen } \\
\text { auf }\end{array}$} & & \multirow{2}{*}{ 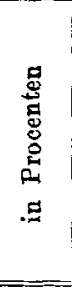 } & \multicolumn{2}{|c|}{ In Behandlung } & \multicolumn{2}{|c|}{$\begin{array}{l}\text { Unterbrochene } \mathrm{Be}- \\
\text { handlung infolge } \\
\text { Mangel an Ausdaner }\end{array}$} & \multirow{2}{*}{$\begin{array}{c}\text { Ausser Be- } \\
\text { handlung }\end{array}$} \\
\hline & & & 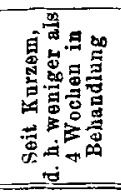 & 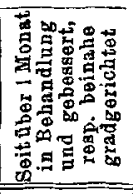 & 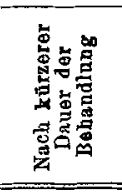 & 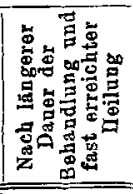 & \\
\hline $\begin{array}{l}\text { Pes varus cong. dupl. } \\
=\quad=\quad=\text { dext. } \\
=\quad=\quad=\text { sin. } \\
=\quad=\text { paral. dext. } \\
=\quad=\quad=\text { sin. } \\
=\quad=\text { traumat. sin. }\end{array}$ & $\begin{array}{r}29 \\
15 \\
8 \\
6 \\
5 \\
1\end{array}$ & $\begin{array}{r}45,4 \\
23,5 \\
12,5 \\
9,3 \\
7,8 \\
1,5\end{array}$ & $\begin{array}{l}\frac{1}{1} \\
- \\
-\end{array}$ & $\begin{array}{l}4 \\
3 \\
1 \\
-- \\
-\end{array}$ & $\begin{array}{l}1 \\
1 \\
- \\
- \\
-\end{array}$ & $\begin{array}{l}2 \\
1 \\
- \\
- \\
-\end{array}$ & $\begin{array}{r}21 \\
10 \\
7 \\
5 \\
5 \\
1\end{array}$ \\
\hline & & 100,0 & 2 & 8 & 2 & 3 & 49 \\
\hline & & 100,0 & 3,2 Proe. & 12,4 Proc. & 3,2 Proc. & 4,6 Proc. & 76,6 Proc. \\
\hline
\end{tabular}

Obige Tabelle ergiebt also, dass:

7,8 Proc. der Patienten die Behandlung aus Mangel an Ausdauer in den verschiedensten Stadien der Heilung aufgaben,

$76,6=$ der Kranken definitive Heilung fanden, welche bei sorgfältiger Nachbehandlung recidivfrei bleiben,

$15,6=$ der Kranken sich in den verschiedensten Stadien der Heilung in Behandlung befinden.

Mitte August 1886 war es mir gestattet, in Gemeinschaft mit meinem Vater die sämmtlichen operativen Pes varus-Fälle eines bedeutenden auswärtigen Chirurgen aus den Jahren 1884 und 1885 in Augenschein zu nehmen, und zwar zum Zweck eines vergleichenden Studiums hinsichtlich ibrer Heilresultate gegentiber den durch die Orthopädie errungenen.

In Folgendem gebe ich die Vorgeschichte der 5 Patienten und den am 17. August 1886, also einige Zeit nach der Operation erhobenen Status. 
I. Lucia Vischer, geboren April 1881.

Pes varus cong. duplex.

Anamnese. Im Alter von 1/4 Jahr Gypsverbände, die $1 / 4 \mathrm{Jahr}$ lang fortgesetzt wurden. Nachher Schuhe mit äusserer Schiene, ohne welche Gehen nicht möglich war. Operation am 9. Juni 1885. Beiderseitige Talusexstirpation mit Alter von $4^{1 / 4}$ Jahren.

Dauer der Behandlung 42 Tage. Entlassen mit Gypsverband, der 7 Wochen liegen blieb. Seitdem geschah nichts mehr; nur Schuhe mit langen und hohen Lederkappen wurden getragen.

Damaliger Status:

Pes dexter. Beweglichkeit activ und passiv im Talocruralgelenk beschränkt. Cuneiforme I bis auf $1 \mathrm{Cm}$. an die Gelenkfläche der Tibia herangertlckt und der Mitte zwischen dem inneren und äusseren Knöchel entsprechend. Os naviculare bis dicht an den vorderen Gelenkrand der Tibia herangeschoben. Metatarsus I und Cuneiforme I verlaufen gegen die Längsaxe des Fusses von hinten aussen nach vorne innen, so dass die

Fig. $9(\mathrm{I})$.

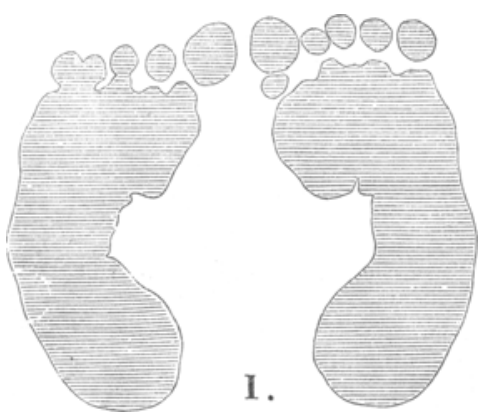

Gelenkverbindung mit dem Os naviculare der Mitte des Raumes zwischen innerem und äusserem Knöchel entspricht. Die äussere Seite des Fusses entsprechend der äusseren Hälfte des Tarsus und Metatarsus bogenförmig mit Convexität nach aussen gewölbt (Fig. $9[\mathrm{I}]$ ). Die Mitte dieses Bogens entspricht der Gelenkverbindung des Calcaneus mit dem Cuboideum. Dementsprechend Faseia plant. gespannt, Supinationsstellung nur theilweise beseitigt. Der äussere Fussrand nach unten (eine Schwiele entsprechend dem Capitul. oss. metatarsi V), der

innere bei horizontaler Lage des Unterschenkels nahezu $3 \mathrm{Cm}$. höher stehend. Beim Stehen berîhrt nur der äussere Fussrand den Boden. Achillessehne nicht gespannt, auch die Spannung anderer Sehnen nicht hervortretend. Zwischen Naviculare und Malleol. int. nach vorne auf $1 / 3$ des vorderen Gelenkrandes der Tibia Hohlranm in sehr entschiedener Weise fühlbar.

Pes sin. Dieselben Erscheinungen wie am rechten Fuss, nur in höherem Grade, namentlich dadurch sich aussprechend"; dass die Tuberositas oss. navic. sehr deutlich fühlbar bis auf ungefähr $2 / 3$ des Raumes zwischen innerem und äusserem Knöchel nach aussen gertickt ist. Im Vergleich zum rechten Fuss ist links die Spannung der Fascia plant. viel grösser, die Planta viel hohler und der Bogen der äusseren Seite des Tarsus und Metatarsus höher. Musculatur: Wadenumfang rechts und links $15 \mathrm{Cm}$.

Gang steif, mehr stossförmig, stelzenartig. Linke Fussspitze stark nach einwärts gebogen beim Gehen.

Winkelmessung: 


\begin{tabular}{|c|c|c|c|c|c|c|c|}
\hline \multicolumn{4}{|c|}{$\begin{array}{c}\text { Rechter Fuss } \\
\text { Winkel }\end{array}$} & \multicolumn{4}{|c|}{$\begin{array}{c}\text { Linker Fuss } \\
\text { Winkel }\end{array}$} \\
\hline I & $\begin{array}{c}\text { Excursion } \\
\text { I }\end{array}$ & II & III & I & $\begin{array}{l}\text { Excursion } \\
\text { I }\end{array}$ & II & III \\
\hline Grad & $\begin{array}{c}\text { Grad } \\
\text { ron } 94 \text { bis } \\
109, \text { also } \\
15\end{array}$ & Grad & Grad & Grad & $\begin{array}{c}\text { Grad } \\
\text { von } 92 \text { bis } \\
105, \text { also } \\
13\end{array}$ & Grad & Grad \\
\hline
\end{tabular}

II. Adolf Schick, geboren 20. October 1881.

Pes varus cong. duplex.

Anamnese. Mit 9 Wochen Sayre'scher Klumpfussverband mit Heftpflasterstreifen und Flanellbinde unter ständiger ärztlicher Controle während der Dauer von 1/4 Jahr. Die Mutter fuhr dann zu Hanse mit der Flanellbindenbehandlung weiter fort. Operation am 1. Februar 1884. Doppelseitige Talusexstirpation, links noch Os cuboides im Alter von $21 / 4$ Jahren.

Patient wurde mit Gypsverband entlassen, der 4-6 Wochen lag; ein zweiter Gypsverband lag ebenfalls 4 Wochen. Seitdem keine Behandlung. - Der Knabe trägt Schuhe mit innerer und äusserer Schiene.

Fig. 10 (II).

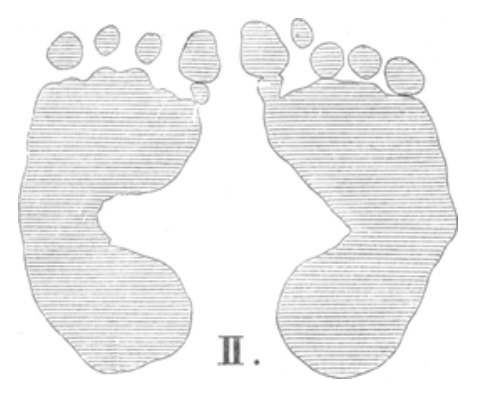

Fig. 11 (III).

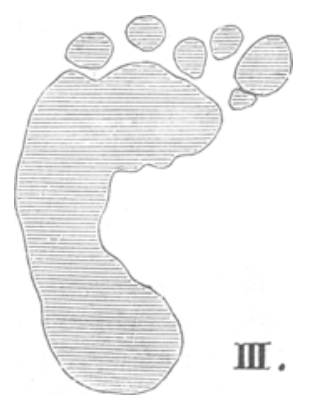

Damaliger Status: Wieder die allgemeinen typischen anatomischen Verhältnisse wie bei Fall 1. Extremitäten nach aussen rotirt. Starke Genu valgum - Stellung im Winkel von $169^{\circ}$ beiderseits. Active und passive Bewegungsfähigkeit im Talocruralgelenk ist vorhanden, links noch bedeutender durch Herausnahme des Cuboid. Der äussere Fussrand rechts mehr gekrlimmt als links, auf welcher Seite die Convexität an der äusseren Seite des Fusses, welche den Ossa cuneif. entspricht, sehr in die Augen fällt (s. Fig. 10). Ebenso tritt die Aushöhlung der Planta und die Spannung der Fascia plant. sehr hervor. Rechts steht die Tuberos. oss. navic. in der Mitte des vorderen Gelenkrandes der Tibia, links noch etwas nach aussen davon.

Der linke Fuss ist gegen den rechten um $1 \frac{1}{1} / 2 \mathrm{Cm}$. verkürzt. Beiderseits findet sich die Tibia auf dem Calcaneus nach hinten gerückt, so dass die Ferse kaum vorsteht. Fersenstand: Links bedeutende Supination, 
rechts geringer, links von $106^{\circ}$, rechts von $97^{\circ}$; Gang klumpfussartig mit stark nach innen gewendeten Fussspitzen, mehr stelzenartig; die grosse Zehe wird namentlich am linken Fuss stark in die Höhe gehoben; Ferse, wie schon bemerkt, stark supinirt, besonders links. Der Knabe geht links auf dem Rand des Calcaneus.

\begin{tabular}{|c|c|c|c|c|c|c|c|}
\hline \multicolumn{4}{|c|}{$\begin{array}{c}\text { Rechter Fuss } \\
\text { Winkel }\end{array}$} & \multicolumn{4}{|c|}{$\begin{array}{l}\text { Linker Fuss } \\
\text { Winkel }\end{array}$} \\
\hline I & $\begin{array}{c}\text { Excursion } \\
\quad 1\end{array}$ & II & III & I & $\begin{array}{c}\text { Excursion } \\
I\end{array}$ & II & III \\
\hline Grad & $\mid \begin{array}{c}\text { Grad } \\
\text { von } 89 \text { bis } \\
107, \text { also }\end{array}$ & Grad & Grad & Grad & $\left|\begin{array}{c}\text { Grad } \\
\text { von } 84 \text { bis } \\
100, \text { also } \\
16\end{array}\right|$ & Grad & Grad \\
\hline 89 & 18 & 77 & 46 & 84 & 16 & 75 & 23 \\
\hline
\end{tabular}

III. Therese Furth, geboren 15. October 1882.

Pes varus cong. sin.

Anamnese. Keine Behandlung vor der Operation.

Operation am 14. Juli 1884. Links Exstirpation des Talus und des Os naviculare im Alter von 13/4 Jahren.

Seit der Operation circa 4-5 Gypsverbände. Seit Frühjahr 1886 Schuh mit innerer und äusserer Schiene.

Damaliger Status. Dasselbe Bild. Tuberos. oss. navic. in der Mitte des vorderen Gelenkrandes der Tibia. Aeussere Convexität des Fusses noch ziemlich bedeutend (s. Fig.11 S. 217). Die von der Operation herrithrende Narbe reicht von der Mitte des vorderen Tibialrandes bis zum Malleol. ext. und ist adhärent. Die Hohlung der Planta ist bedeutend, desgleichen die Spannung der Fascia plant. Es findet sich eine beschränkte active und passive Beweglichkeit im Talocruralgelenk. Das Mädchen geht auf dem äusseren Fussrand und einem Theil der anstossenden Aussenseite des Fussrïckens, an welchen Stellen man Schwielen wahrnimmt. Calcaneus in nicht unbedeutender Supinationsdrehung.

Wadenumfang links $141 / 2$, rechts $161 / 2 \mathrm{Cm}$. $2 \mathrm{Cm}$. Verkürzung des linken Beines, die im Unterschenkel liegt. - Gang auf änsserem Fussrand und Ferse.

\begin{tabular}{l|c|c|c}
\hline \multicolumn{4}{c}{$\begin{array}{c}\text { Linker Fus } \\
\text { Winkel }\end{array}$} \\
\hline I & $\begin{array}{c}\text { Excursion } \\
\text { I }\end{array}$ & II & III \\
\hline Grad & $\begin{array}{c}\text { Grad } \\
\text { ron } 85 \text { bis } \\
106, \text { also } \\
11\end{array}$ & Grad & Grad \\
\hline 50 & 40
\end{tabular}

IV. Pauline Wirth, geboren 12. Juli 1879 .

Pes varus cong. sin.

Anamnese. Ein älterer Bruder leidet an hochgradigen doppelseitigen 
Klumpfüssen. Das Kind wurde im Alter von 1 Jahr mit Gypsverbänden behandelt.

Operation am 15. December 1884. Exstirpatio tali sin. nach vorheriger Achillotenotomie im Alter von 5 Jahren 5 Monaten.

Zur Zeit der Operation bestand am linken Fuss hochgradige Adduction, so dass die Fussspitze vollständig nach innen sah. Der Fuss war nach aussen rotirt, das Kind trat auf die äussere Hälfte des Fussrückens auf. Starke Schwiele, entsprechend der Gegend des Os cuboid. Knie in leichter Varusstellung, die Condyli femoris etwas nach aussen rotirt.

Der exstirpirte Talus zeigte im Halstheil eine nahezu rechtwinkelige Abknickung.

Am 28. Tage nach der Operation war die Wunde geschlossen. 14 Tage später bekam das Mädchen den Sayre'schen Heftpflastergummizug und fing dann an zu gehen. 2 Monate nach der Operation wurde sie mit hohem Schnürstiefel und dem Say re'schen künstlichen Muskel entlassen. Sie soll damals ziemlich gut haben gehen können. Anstatt das Kind in einigen Wochen wieder vorzustellen, brachte die Mutter dasselbe erst nach 31/2 Monaten, also $5 \frac{1}{2}$ Monate nach der Operation. Das Mädehen war ohne Verband, ein mässiger Varus hatte sich wieder ausgebildet, sonst soll der Fuss gut und ohne Adduction gestanden haben. Der Fuss wurde in leichter Valgusstellung eingegypst.

6 Wochen später wurde der Gypsverband abgenommen. Der Fuss soll in guter Stellung gewesen sein. Ein leichter Verband mit Sayreschem Muskel wurde angelegt, worüber ein hoher Schnürstiefel kam.

Damaliger Status, d. h. 1 Jahr 8 Monate nach der Operation. Typische Verhältnisse wie bei den vorhergehenden Fällen. Tuberos. oss. nav. über die Mitte des vorderen Gelenkrandes der Tibia nach aussen stehend. Hohlung der Planta in erheblichem Maasse fortbestehend bei entsprechender Spannung der Fascia plant. (Fig. 12 [IV] S. 220). Beweglichkeit im Talocruralgelenk fast nahezu aufgehoben, anscheinend rechtwinkelige Ankylose im Talocruralgelenk. Calcaneus in nicht nnerheblicher Supination. Die linke Extremität zeigt eine Verkürzung von $31 / 2 \mathrm{Cm}$, die im linken Unterschenkel liegt.

Wadenumfang rechts 23 , links $18 \mathrm{Cm}$. Atrophie des linken Beines. Links Genu valgum von 171\%. Gang stelzenartig. Das Kind tritt links nur auf dem hinteren Theil des äusseren Fussrandes, d. h. auf Cuboid und Calcaneus auf. Der Fuss wird eigentlich nicht gebraucht, sondern bewegungslos mitgeführt.

\begin{tabular}{c|c|c|c}
\hline \multicolumn{4}{c}{$\begin{array}{c}\text { Linker Fuss } \\
\text { Winkel }\end{array}$} \\
\hline I & $\begin{array}{c}\text { Excursion } \\
\text { I }\end{array}$ & II & III \\
\hline $\begin{array}{c}\text { Grad } \\
91\end{array}$ & $\begin{array}{c}\text { Grad } \\
\text { Keine }\end{array}$ & $\begin{array}{c}\text { Grud } \\
78\end{array}$ & $\begin{array}{c}\text { Grad } \\
49\end{array}$
\end{tabular}

V. August Dietz, geboren 28. August 1884.

Pes varus cong. duplex.

An amnese. Keine Behandlung vor der Operation. 
Operation am 7. Januar 1885. Exstirpatio tali utriusque im Alter von etwas über 4 Monaten.

Wurde nach der Operation mit Gypsverband entlassen, der 3 Wochen getragen wurde. Ein zweiter Gypsverband lag ebenfalls 3 Wochen. Seitdem geschah nichts mehr.

Damaliger Status, d. h. circa 1 Jahr nach der Operation. Im Allgemeinen sind die Verhältnisse dieselben wie im Fall 1. Der linke Fuss entschieden mehr verkrümmt als der rechte (s. Fig. 13 [V]). Fascia

Fig. 12 (IV)

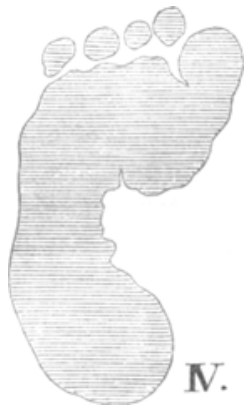

Fig. 13 (V).

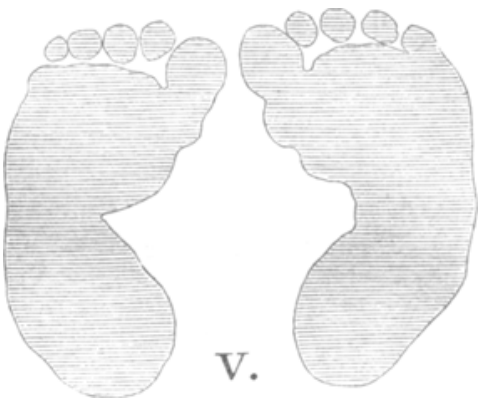

plant. stark gespannt und die Hohlung der Planta sehr bedeutend, dem entsprechend stellt sich anch die an der äusseren Seite des Tarsus und Metatarsus hervortretende Wölbung dar. Starke Beweglichkeit in den Gelenken zwischen $\mathrm{Os}$ metatars. V und Cuboid und zwischen letzterem und dem Calcaneus. Die 'Tuberos. oss. navic. rechts in der Mitte des vorderen Gelenkrandes der Tibia stehend, links etwas uber die Mitte nach aussen.

Ferse in Supinationsdrehung, links viel mehr als rechts. Der linke Fuss, wenn abducirt und dorsalfectirt, ergiebt mässige Spannung der Achillessehne.

Wadenumfang beiderseits $17 \mathrm{Cm}$.

Kniee zeigen Valgusstellung und die ganze Extremität rechts und links geringe Rotation nach aussen.

Gang vollständig mit nach einwärts gewendeten Fussspitzen, nicht allein auf dem äusseren Fussrande, sondern mehr anf der äusseren Seite des Fusses.

\begin{tabular}{|c|c|c|c|c|c|c|c|}
\hline \multicolumn{4}{|c|}{$\begin{array}{c}\text { Rechter Fuss } \\
\text { Winkel }\end{array}$} & \multicolumn{4}{|c|}{$\begin{array}{c}\text { Linker Fuss } \\
\text { Winkel }\end{array}$} \\
\hline I & $\begin{array}{c}\text { Exenrsion } \\
\text { I }\end{array}$ & II & III & I & $\begin{array}{c}\text { Excursion } \\
\text { I }\end{array}$ & II & III \\
\hline Grod & $\left|\begin{array}{c}\text { Grad } \\
\text { von } 95 \text { bis } \\
113, \text { also } \\
18\end{array}\right|$ & Grad & Grad & Grad & $\mid \begin{array}{c}\text { Grod } \\
\text { von } 90 \text { bis } \\
109, \text { also } \\
19\end{array}$ & Grad & Arad \\
\hline
\end{tabular}


Wir haben im Vorhergehenden die Thatsachen reden lassen, sie sprechen so laut und deutlich, dass sie uns eigentlich jeden Commentars entheben.

Der aufgenommene Status der 5 mit T'alusexstirpation behandelten Fälle führt zu folgendem Schlussresultat: Die Deformität der Füsse ist noch in allen Fällen eine hochgradige, der Gang steif, stelzenartig, mit stark adducirten Fussspitzen, meist bedeutender Supination; die Kinder treten auf dem äusseren Fussrand und zum Theil auf der Aussenseite des Fusses auf.

Fủr die Richtigkeit dieser Auffassung sprechen die Fussabdrücke, die das Bild eines uncorrigirten Pes varus zeigen, ferner die Aufnahme der Winkel.

I. Winkel. Ziemlich corrigirt ist die Plantarflexion, die Winkel von $94^{\circ}$ und $92^{\circ}, 89^{\circ}$ und $84^{\circ}, 85^{\circ}, 91^{\circ}, 95^{\circ}$ und $90^{\circ}$ ergiebt mit einer Excursion von im 1. Fall rechts $15^{\circ}$, links $13^{\circ}$; im 2. Fall rechts $18^{\circ}$, links $16^{\circ}$; im 3. Fall links $11^{\circ}$; im 4. Fall Beweglichkeit im Talocruralgelenk aufgehoben; im 5. Fall rechts $18^{\circ}$, links $19^{\circ}$.

II. Winkel. Die Supination ergiebt Winkel von $80^{\circ}$ und $79^{\circ}$, $77^{\circ}$ und $75^{\circ}, 70^{\circ}, 78^{\circ}, 84^{\circ}$ und $80^{\circ}$, also eine nur wenig oder gar nicht corrigirte Supination.

III. Winkel. Mit Rücksicht auf die Adduction zeigen die 5 Fälle eine sehr mässige Formverbesserung, es finden sich Winkel von $41^{\circ}$ und $45^{\circ}, 46^{\circ}$ und $23^{\circ}, 40^{\circ}, 49^{\circ}$ und $47^{\circ}$, welche für eine noch bestehende hochgradige Adduction sprechen.

Der objective Beobachter kann also nicht umbin, auszusprechen, dass die Talusexstirpation, obgleich deren vorzügliche Resultate immer und immer wieder in der Literatur an der Hand angeblich geheilter Fälle hervorgehoben werden, die Heilung des Pes varus nicht bewirkt. Leider ist aber nach diesem bedentenden Eingriffe in das Skelet die Herstellung'der natürlichen Form des Fusses, des natürlichen Mechanismus der Gelenke und der Elasticität des Ganges durch die Hülfe der mechanischen Orthopädie ausgeschlossen.

In der von meinem Vater auf dem XV. Chirurgencongress aufgestellten V. These wird "die Möglichkeit der Heilung eines jeden Klumpfusses durch die mechanische Orthopädie ausgesprochen, mit der einzigen Ausnahme, dass es sich um einen in so hohem Grade schmerzhaft gewordenen Klumpfuss in einem Alter und unter Verhältnissen handelt, wo die orthopädische Behandlung wenig Aussicht auf Erfolg bietet und wo die Resection gewissermaassen die Amputation des Gliedes ersetzen soll ".

Die Zusammenstellung der von Dr. Krauss behandelten Fälle 
zeigt, dass es sich in der îberwiegenden Mehrzahl der Fälle um hochgradige Klumpfüsse, solche 2. und 3. Grades, handelt; das Gesammtergebniss der Heilungen spricht in uberzeugender Weise für die Wirksamkeit der mechanischen Orthopädie auch bei hochgradigen Fällen von Pes varus und damit für die Richtigkeit der V. These. Die auf dem Chirurgencongress besprochenen Fälle in London von meinem Vater in den Jahren 1837-1843 behandelter und geheilter angeborener Klumpfüsse höchsten Grades, im Alter von 15, 20, 28 und 32 Jahren, deren Gypsabgiisse vorgelegt wurden, zeigen, dass auch ohne operative Eingriffe durch mechanische Orthopädie Heilung in diesem Lebensalter möglich ist.

Als weiteren Beleg möchte ich noch den Fall 58, Magdalene Strohmenger, anführen, eine im 37. Lebensjahre stehende Frau mit Pes varus paral. dexter, welche, wie in der Tabelle angegeben, zur Amputatio pedis bestimmt war und deren Fussverkrümmung soweit beseitigt ist, dass Winkel I unter $90^{\circ}$, Winkel II $=90^{\circ}$ und Winkel $\mathrm{III}=0^{\circ}$ ist und die Kranke bereits einige Schritte auf dem Fuss gehen kann.

"Die besten Beweise für die Verbesserungen meiner Behándlungsmethode ", sagt Dr. Krauss ${ }^{25}$ ), „waren die bei congenitalen Klumpfüssen höchsten Grades und bei Personen vorgeriickten Alters bewirkten Heilungen.

Die Ursache meines Erfolges ist darin zu suchen, dass ich mich specieller der Orthopädie gewidmet und besondere Befriedigung bei diesem Studium gefunden habe."

Mechanische und operative Orthopädie bei Behandlung des Pes varus. Ihre Fürsprecher and Gegner.

Bei den vielfachen Fragen, die sich bei Verfassung einer $\mathrm{Ab}$ handlung tiber die orthopädische Therapie des Klumpfusses aufdrängen, den vielfach sich widersprechenden Ansichten, die im Laufe der Zeiten die verschiedensten Wandlungen durchgemacht, und bei der umfangreichen Literatur wtirde es den Rahmen dieser Arbeit weit thberschreiten, wenn wir alle in Betracht kommenden Momente berühren wollten. Hauptzweck dieser Arbeit ist es, in der Jetztzeit, wo die operative Chirurgie infolge des Lister'schen Verfahrens einen so ungeahnten Aufschwung genommen, wo sie täglich durch neue, klihne Eingriffe bewundernswerthe Erfolge erringt, dazu beizutragen, dass ein Gebiet, dem sie sich eine Zeit lang scheinbar nicht .ohne Erfolg zuzuwenden schien, wieder der alten Schule der mechanischen 
Orthopädie zuerkannt werde. Die Erfolge mechanischer Orthopädie bei Pes varus stellten wir im vorhergehenden Kapitel denen der Talusexstirpation, welche anerkanntermaassen von allen operativen Verfahren die besten Resultate liefert, gegenüber. Im Folgenden stellen wir die Ansichten aller derjenigen Autoren zusammen, die sich seit 1850 über die verschiedenen Behandlungsmethoden bei Pes varus geäussert, soweit wir darüber Angaben in der Literatur finden konnten, und zwar behandeln wir:

I. Operative Methoden, insofern solche das Knochengerüst des Fusses in Angriff nehmen:

1. die Keilresection,

2. die Talusexstirpation,

und im Gegensatz dazu

die Einwendungen, die die Gegner jeden operativen Eingreifens in das Knochenskelet des Fusses diesem Verfahren gemacht haben.

II. Die operative Methode, welche sich auf die Weichtheile des Fusses beschränkt, die Phelps'sche Methode.

\section{I, 1. Die methodische Keilresection.}

In Deutschland durch Meussel und Schede eingeführt.

Für dieselbe sprechen sich aus:

$\mathrm{K} \ddot{\mathrm{n}} \mathrm{ig}{ }^{4}$ ), welcher angiebt, dass er die Keilresection für sicherer als das früher von ihm ausgeführte Redressement forcé halte, weil dieses auch nur mit Auswahl möglich war und, falls man den Gypsverband der Gradrichtung sofort folgen liess, von dem Brand der Extremität gefolgt sein konnte.

An anderer Stelle ${ }^{1}$ ) spricht sich derselbe Autor dahin aus, , dass man die recidiven Klumpfiusse des Kindes nur dann durch Keilexcision grade machen soll, wenn man die übrigen Methoden vergeblich versucht hat. Dagegen soll man sich bei den vernachlässigten Klumpfiussen Erwachsener oder fast Erwachsener, seien sie congenitale oder paralytische, angesichts der Einfachbeit und Sicherheit der Cur nicht mit den anderen unsicheren und langwierigen Methoden aufhalten".

Roser ${ }^{5}$ ): „Ich darf aber hervorheben, dass ich durch eine weniger eingreifende Operation (als die Talusexstirpation), die Osteotomia cuneiformis tarsi, bei vier hochgradigen Klumpftussen sehr gute Resultate erzielt habe. ${ }^{\text {" }}$

Macewen $\left.{ }^{6}\right)$ : „Nur in sehr schweren Fällen von congenitalem Klumpfuss ist zur Osteotomie oder Keilexcision zu rathen." 
Dr. Hirschberg ${ }^{7}$ ) (Frankfurt a/M.) $:{ }_{n}$ Eigentlich in den seltensten Fällen bat man nach einer bestimmten Methode operirt. Jeder hat nach Belieben von den Knochen weggenommen. Von den Malleolen an bis zum Metatarsus wurden alle Knochen nach Gutdünken weggemeisselt, oder exarticulirt, oder resecirt. - Das müssen wir doch sagen, dass die anatomischen Verbältnisse uns bei der Operation eigentlich ganz im Stich gelassen haben.

Wenn wir aber nicht von anatomischen Verbältnissen geleitet werden, müssen wir das ganze untere Extremitätenstick, d. h. Malleolen sammt Fuss, als ein verunstaltetes Ganze, als ein Stiuck aus einem Guss betrachten, und wir haben die Aufgabe zu lösen, dieses Stück so umzuformen, dass es der normalen Fussform möglichst nahe kommt. Wir müssen durch Berechnung die Lage und Grösse des zu entfernenden Stückes bestimmen. So werden wir mit dem möglichst kleinen Substanzverlust den möglichst vollkommenen Effect erzielen. Ein Mathematiker, Prof. G. Zehfuss in Frankfurt a/M., hat diesen Keil durch Berechnung bestimmt. Nach dieser Methode habe ich seit 5 Jahren mit durchaus zufriedenstellenden Resultaten operirt. Die Formen der Füsse nähern sich möglichst der Norm, dann aber sind sowohl das Talocrural- wie das Chopart'sche Gelenk intact geblieben.

Wie die Form der congenitalen Klumpfüsse in den meisten Fällen eine typische ist, so wird auch die Operation in typischer Weise ausgeführt. Die Lage des Keils ist mit seltenen Ausnahmen eine gegebene. Der zu entfernende Keil ist immer vorn herauszulösen, vor dem eigentlichen Buckel, d. h. vor der Fussgelenks- und Chopartschen Linie, so zwar, dass die vordere Keilseite in die Lisfranc'sche Linie fällt, die bintere Seite in den Metatarsus hinein, und zwar derart, dass das Chopart'sche Gelenk meistentheils, das Fussgelenk immer vollständig intact bleibt. Es ist ganz erstaunlich, wie leicht sich der Fuss alsdann nach Durchschneidung der Fascia plantaris und der Achillessehne redressiren lässt."

Als Gegner der Keilresection treten auf:

Wolff ${ }^{8}$ ): "Die von Hirschberg empfoblene Resection trifft der Vorwurf, dass bei derselben wiederum ganz beliebige Theile des Fussskelets ohne alle Rücksicht auf die anatomische und physiologische Bedeutung, welche denselben für die spätere Form und für die späteren Wachsthums-und Ernährungsverhältnisse des Fusses zukommt, entfernt, resp. verletzt werden."

Vogt $\left.{ }^{9}\right)$ : „Immerhin aber bleibt es erwünscht, dass man sich 
aus dem pathologisch-anatomisehen Object klar wird über die Maassnahmen and nicht für alle Fälle das Tarsalgerüst als eine difforme, feste Masse betrachtet, aus der man ad libitum ohne Berticksichtigung der einzelnen Knochen und Gelenke einen Keil herausmeisselt, um die Correction der Verkrümmung zu erzielen. Dies letztere könnte nur für den verknöcherten Klumpfuss des Erwachsenen gerechtfertigt sein. Beim kindlichen recidivirten oderveralteten Klump. fuss ist immer noch eine nicht unerhebliche Verschiebbarkeit der Tarsalknochen vorhanden, die zur Verlegung der Druckpunkte auf die gewucherten Tarsalabschnitte benutzt werden kann."

An einer anderen Stelle desselben Werkes sagt Vogt: „Durch die tarsale Osteotomie, die im Allgemeinen nach dem Typus einer partiellen oder totalen keilförmigen Resection des Chopart'schen Gelenkes anzulegen ist, wird immer eine Verkürzung des Fussskelets gesetzt. Statt dessen: Exstirpatio tali. - -

Bei den veralteten Klumpfüssen Erwachsener verdient die Osteotomie a priori den Vorzug, doch ist in manchen Fällen die Verkümmerung der Extremitäten derartig, dass doch nur eine stelzenähnliche Fussform durch die hier immer nöthige ausgedehnte Resection gewonnen werden könnte."

Dr. Krauss 10 ): „Vergleiche ich die Ergebnisse der Resection mit den Fällen von Klumpfuss, die auf andere Weise Heilung gefunden haben, so muss ich zunächst erwähnen, dass ich 1881 in London in einem Hospitale 3 Operirte sah, bei welchen nicht keilförmige, sondern parallele Ausschnitte senkrecht aus der ganzen Dicke des Fusses in der Richtung des Chopart'schen Gelenkes genommen waren. Zwei von diesen Fällen zeigten bei ziemlicher Ausgleichung der Supinationsverdrehung colossale Anschwellungen, aber eine Verlagerung des vorderen Theiles des Fusses nach aussen, die nur sehr störend auf die Function des Fusses wirken konnte.

In mehreren Fällen wirklicher Keilresection fand ich, dass die Verbesserung in der Stellung des Fusses eine sehr geringe war, während ich wieder andere Fälle beobacktete, in welchen die Supinationsverdrehung ziemlich ausgeglichen war; bei allen Fällen sah ich Erhebung, d. h. Hochstehen der Ferse."

Weiss ${ }^{11}$ ) drückt seine Meinung dahin aus, dass die Talusexstirpation der Keilexcision aus dem Tarsus bei schweren Fällen von congenitalem und acquirirtem Klumpfuss stets vorzuziehen sei.

Ried 12) theilt uns 4 Fälle von congenitalem Pes varus mit, an denen die keilförmige Operation aus dem Tarsus im Alter von 7 Mo- 
naten, $33 / 4$ und zweimal von 3 Jahren vorgenommen wurde. Er selbst kommt zu dem Schluss: „Nach den von uns gemachten Erfahrungen kann ich also die Keilresection aus dem Tarsus bei jugendlichen Klumpfusskranken keineswegs em. pfehlen."

Bessel-Hagen ${ }^{13}$ ) giebt an, dass von 122 keilförmigen Osteotomien aus der lateralen Hälfte des Tarsus, abgesehen von 5 Todesfällen, 45 Fälle ein bestimmt schlechtes Resultat gehabt haben, dass in mehr als 20 Fällen ein Recidiv bekannt geworden ist.

\section{I, 2. Die Talusexstirpation.}

Für dieselbe sprechen sich aus:

Boeckel ${ }^{14}$ ). Derselbe unterscheidet Pieds-bots tendineux und osseux; bei den einen sind die Sehnen, bei den anderen die Knochen, speciell der Talus, Haupthinderniss des Redressement. Die zweite Form soll selbst nach sehr ausgedehnter Behandlung durch Tenotomie, Massage und Maschinen leicht recidiviren, die Tenotomie soll bei ihr ohne Erfolg sein.

"Die Ursache der Recidive liegt nach Boeckel in der ungenügenden Dorsalflexion des Fusses. Während beim normalen Fuss eine spitzwinkelige Flexion am Ende des Schrittes stattfindet, ist dies bei Kindern mit Pes varo-equinus unmöglich, sie helfen sich dadurch, dass sie den Fuss adduciren und um seine Längsaxe drehen. Wenn die Varusstellung auch vollständig corrigirt ist, so wird auf diese Weise bei nicht gleichzeitiger absoluter Beseitigung des Equinus unfehlbar ein Recidiv eintreten.

Zur vollständigen Correction des Spitzfusses gehört aber die Möglichkeit der Dorsalflexion etwas über den rechten Winkel. Haupthinderniss ist die Difformität des Talus, seine Exstirpation that den Functionen des Fusses keinen Schaden und nach ibr gelingt das Redressement. “

Macewen ${ }^{6}$ ) hat die Talusexstirpation in $4-5$ Fällen ausgefubrt, konnte sich jedoch noch kein endgültiges Urtheil ther ihren Werth bilden.

Weiss ${ }^{11}$ ) plaidirt bei schweren Fällen von congenitalem und acquirirtem Klumpfuss, wenn die orthopädischen Behandlungsmethoden incl. Tenotomie im Stich lassen, für Enucleation des Talus, welche er der Keilexcision aus dem Tarsus stets vorzieht.

Nach Nicolaysen ${ }^{15}$ ) kommt man bei alten Fällen von congenitalem Pes equino-varus, wo die Patienten schon lange umber- 
gegangen sind, mit orthopädischen Maassnahmen nicht aus. Verfasser macht in diesen Fällen Excision eines oder mehrerer Knochen der Fusswurzel. Er bespricht dann noch speciell seine Methode der Talusexstirpation.

Tilla ux ${ }^{16}$ ) glaubt, dass bei Individuen von $20-30$ Jahren die Methoden von Guérin (mechanische Ortbopädie) nichts nützten, hier könne nur die Tarsotomie zur Heilung führen.

Lorenz ${ }^{17}$ ) kommt zu dem Resultat, dass am intacten congenitalen Klumpfuss die Talusenucleation das beste Resultat liefert. Später bietet die Keilexcision aus der Fusswurzel mehr Vortheil.

Wanscher ${ }^{18}$ ) will bei Erwachsenen, wenn man nicht mit dem Redressement durchkommen kann, die Tarsotomie und am liebsten die Talusexstirpation machen.

Bessel-Hagen ${ }^{13}$ ): „Die hochgradig veralteten Fälle von Klumpfuss dagegen, bei denen das Verhalten der Knochen und Gelenke ein solches ist, dass eine Correctur der Deformität nur mit sehr schweren Knochenzertrümmerungen und Zerreissungen möglich ist, indiciren die Resection des Talus. Das blosse Herausholen des Talus ist indessen nicht hinreichend, es ist ausserdem principiell die Lösung des Calcaneus von der Fibula erforderlich.

Unter 64 Talusenucleationen, von denen 11 mit Keilexcision verbunden waren, ist das Resultat, von einem Todesfall abgesehen, nur $6 \mathrm{mal}$ ein unvollkommenes und schlechtes gewesen, dagegen $57 \mathrm{mal}$ ein gutes."

Im Anschluss an seinen Vortrag auf dem XIV. Chirurgencongress stellte Bessel-Hagen 2 Patienten vor, bei denen wegen schwerer congenitaler Klumpfüsse die Talusenucleation ausgefuhrt worden war, ein $12 \frac{1}{2}$ jähriges Mädchen und einen 24 jährigen Herrn.

Gegner der Talusexstirpation.

Der auf Herrn Bessel-Hagen folgende Redner auf dem XIV. Chirurgencongress:

Herr Dr. Hirschbergi) spricht sich in folgender Weise aus: "So grosses Interesse die anatomischen Auseinandersetzungen des Herrn Bessel-Hagen erregt haben, so glaube ich doch nicht, dass, namentlich nachdem wir jetzt seine mit Talusexstirpation gewonnenen Resultate gesehen, man diese Operation vorläufig als das Ideal der operativen Massnahmen bei der Behandlung des Klumpfusses betrachten wird. Ich finde zunächst, dass beide Patienten sehr unsicher und unbeholfen gehen, dass sie auftreten, wie wenn sie noch recht 
kranke Fusse hätten, und die Form selbst ist doch anch keine der Norm nabe kommende."

Roser $\left.{ }^{5}\right):$ "In letzter Zeit ist, namentlich durch Vogt, die Talusexstirpation in den Vordergrund der Klumpfussbehandlung gestellt worden. $\operatorname{Vog} \mathrm{t}^{*}$ ) beginnt bei allen höheren Graden von Pes varus, ja sogar des Pes valgus cong., gleich beim Neugeborenen die Behandlung mit der Exstirpatio tali. ,Nur auf diesem Wege gelingt es', sagt $\operatorname{Vog} t$, rasch und sicher diese angeborene Belastungsdeformität zu beseitigen.' Vogt exstirpirt den Talus, weil ihm alle übrigen Behandlungsweisen nicht genug leisten. Er macht z. B. gegen den Gypsverband alle möglichen Einwürfe. Dieselben sind jedoch leicht zu entkräften. - - Vogt $\mathrm{r} u \mathbf{h} m \mathrm{t}$ die Exstirpatio tali als die sicherste und bequemste Methode der Klumpfussbehandlung - sie ist aber auch die eingreifendste und sie verstümmelt das Fussskelet am meisten."

Roser ${ }^{5}$ ) führt einen Fall von Pes equino-varus traumaticus mit Luxatio tali bei einem 44 jährigen Maurer an, der aus 5 Meter Höhe auf den rechten Fuss fiel. Trotz der Exstirpation des Talus bildete sich eine hochgradige Equino-varus-Stellung aus, die später durch Operation und kraftvolles Redressement in der Narkose corrigirt werden musste.

De Forest Williard ${ }^{20}$ ) verwirft bei Kindern die Talusexstirpation, indem man durch manuelle und Maschinenbehandlung mit Hinzufügung eventuell nöthig werdender subcutaner Tenotomien günstige Erfolge erzielen könne, ohne dieselben den Gefabren operativer Behandlung auszusetzen.

$\mathrm{Wolff}^{8}$ ) demonstrirte dann auf dem XIV. Chirurgencongress an 5 Patienten, dass man durch sehr viel einfachere Mittel, als durch die Talusexstirpation oder durch die Keilexcision oder ähnliche schwere operative Eingriffe am Knochengeriust des Fusses zu besseren Resultaten zu gelangen vermag, als sie mittelst der genannten Knochenoperationen jemals erreichbar sein werden ".

"Es ist offenbar", sagt Wolff, "dass die nach der Talusexstirpation eingetretenen guten Resultate der Hauptsache nach gar nicht der Talusexstirpation als solcher zugeschrieben werden düfen. - Ausser dem Talus sind auch noch sämmtliche übrigen Knochen der Extremität deform, das ganze Fussskelet mit Einsehluss der Metatarsen und Phalangen, ja selbst die Unterschenkelknochen und das Femur und die Patella und das Knie- und Hüftgelenk. Die Exstirpatio tali kann also

*) Mittheilungen aus der chirurg. Klinik zu Greifswald. 1884. S. 174. 
an der Deformität der sämmtlichen übrigen Knochen der Extremität zunächst gar nichts ändern. - - Die Talusexstirpation hat ihrem Wesen nach lediglich die Bedeutung der das Redressement erleichternden Continuitätstrennung, also genau dieselbe Bedeutung, wie die demselben Zweck dienenden Tenotomien, wie die lineären und keilförmigen Osteotomien und die $\mathrm{Phelps}$ 'schen Durchschneidungen. - - In der richtigen und vollen Ausnutzung der „Transformationskraft", also in der möglichst sofortigen Herstellung richtiger statischer Verbältnisse und in der Herstellung einer möglichst vollkommenen Function unter diesen richtigen Verhältnissen werden wir, wie ich glaube, fortan die nicht nur bei kindlichen, sondern auch bei erwachsenen Individuen zu erfüllenden Aufgaben der orthopädischen Chirurgie zu suchen baben.

Gegen jede Knochenoperation sprechen sich aus:

Wo Iff , J. ${ }^{19}$ ) (Berlin), stellte auf dem XIII. Chirurgencongress 8 Patienten vor, die sämmtlich durch mechanische Orthopädie (krattvolles Redressement durch einen portativen, in einem gewöhnlichen Stiefel, einem festen Strumpfe gleich zu tragenden Wasserglasverband), der 7-9 Monate liegen bleibt, geheilt sind und normal auftreten; 7 befinden sich im Alter von 6-10 Jahren (3 mit paralytischem Klumpfuss, 2 mit congenitalem, 1 unbestimmt), einer ist 24 Jahre alt (paralytischer Klumpfuss).

Nach seinen Erfolgen glaubt Wolff aussprechen zu dürfen, dass vielleicht in $\mathrm{Zukunft}$ alle schweren operativen Eingriffe bei der Behandlung des congenitalen und paralytischen Klumpfusses in der Regel werden vermieden werden können.

In der sich an diese Mittheilung anschliessenden Discussion spricht sich Volkmann dahin aus, ndass Wolff ansnahmsweise glückliche Fälle von Klumpfüssen vor sich gehabt habe, meistens paralytische Formen, Fälle, die viel behandelt, schon oft gedehnt, in Schienen gegangen sind. Die Verbände, die Wolff anlegt, seien sehr gut, die Füsse der vorgestellten Kranken seien in guter Stellung, weitergehende Schlüsse dürften sich aber nicht ziehen lassen."

Sayre ${ }^{3}$ ) giebt an, dass das beste Mittel, den congenitalen Pes varus gleich nach der Geburt ohne Tenotomie zu heilen, anhaltende Manipulationen und das Halten des Fusses in gehöriger Lage durch die Hand der Wärterin wäre. Dies sei leider eine unmögliche Be- 
handlung. Kein Instrument besitze die Eigenschaften, sich an die Theile anzulegen und an denselben seine Kraft so schmerzlos anzuwenden, wie eben die menschliche Hand.

Sayre behandelt die Contractur der Fusswurzel mit der Filzschiene von A hl, mit Heftpflasterverbänden, mit dem elastischen Zug von Barwell und mit dem von ihm verbesserten Klumpfussschuh, der dem Mediotarsalgelenk gegenutber in der Sohle ein Schannier hat. Dazu active und passive Bewegungen, Massage, Bäder und Elektricität. Die Tenotomie wird nur in schweren Fällen zur Hülfe genommen.

Der Knochenoperationen bei Pes varus erwähnt Sayre in seinem Buche therhaupt nicht einmal.

Lorenz ${ }^{17}$ ) erkennt an, dass die mechanische Orthopädie unter allen Umständen bessere Resultate erzielt. Er sagt: „Die functionellen und formalen Resultate (der operativen Behandlung bei Pessarus) stehen aberweit zur ick hinter jenen der rationellen, mechaniscn Orthopädie, die ihr Ziel am wachsenden Fuss (also diesseits der $20 \mathrm{er}$ Jahre) ausnahmslos anf einem zwar längeren, aber völlig ungefährlichen Wege erreicht.

Der einzige Vortheil der Knochenoperationen besteht in der Kulrze der Behandlungsdauer, es sind also bei der Wahl der Behandlungsmethode wesentlich die socialen Verhältnisse maassgebend. "

Dr. Krauss ${ }^{10}$ ) in der auf S. 221 angefïhrten, auf dem XV. Chirurgencongress aufgestellten $\mathrm{V}$. These.

Wanscher ${ }^{18}$ ) verwirft bei Kindern die Operation am Knochensystem und will nur Redressement forcé, wo möglich in einer Sitzung, von Tenotomien und Phelps' Operation unterstiitzt anwenden.

A. Philippson ${ }^{23}$ ) kommt zu dem Schluss: „Es ist hieraus ersichtlich, dass keiner dieser operativen Eingriffe (Entfernung des Os cuboides, Talusexstirpation selbst mit Durchschneidung des beim alten congenitalen Klumpfuss verkturzten Lig. calca neofibulare, Keilausschnitt) darnach angelegt ist, Garantien fur einen nach jeder Richtung hin befriedigenden Erfolg zu bieten. Wenn auch noch so viele gute Resultate durch eine dieser oder ähnliche Methoden erzielt wurden, so ist damit doch nicht ausgesprochen, dass die Grundlage, auf welcher diese Operationen beruben, eine richtige ist. Den Ausgangspunkt zu den oben angefuhrten Eingriffen bietet die Anschauung, dass sowohl der Klumpfuss am Lebenden, als auch das Präparat mehr oder weniger starke typische Knochenverbildungen zeigt, aus denen die Deformität abzuleiten ist. Bald wurde dieser, bald jener Fussknochen als der 
wesentlichste Bestandtheil der Verkrümmung betrachtet. Auf der anderen Seite setzte oft, selbst bei ganz jugendlichen Individuen, der verkrümmte Fuss dem Correctionsversuch einen so energischen Widerstand entgegen, dass man sich berechtigt glaubte, die stark verbildeten Knochen in Zusammenhang mit dem Widerstand zu bringen. Eine gewisse Bestätigung fand diese Ansicht in dem Experiment, dass nach Entfernung des einen oder anderen Knochens der Hauptwiderstand gebrochen schien und nur eine Federung hinterblieb. Aber diese Federung genügte, falls nicht lange Behandlung eintrat, den gewonnenen Erfolg zu vernichten."

Guérin 21)*) im Jahre 1882. Verfasser ist bei der Behandlung der Klumpfüsse jeden Grades und jeder Form mit der Tenotomie, resp. Syndesmotomie, zweckmässigen Manipulationen und Verbänden, resp. Apparaten ausgekommen. Derselbe verfügt jetzt über mehr als 500 Fälle, in denen der Erfolg nur dann scheiterte, wenn die Kranken zu unvernüftig waren, oder sich der Behandlung entzogen. $\mathrm{G} u$ érin ist daher entschiedener Gegner der jetzt ublichen Knochenoperationen, die Kranken seien mit ihren noch so hochgradigen Klumpfüssen weit widerstandsfähiger, als nach einer noch so glücklichen Operation.

Guérin erklärt die Tarsotomie bei Kindern für einen der schwersten Missbräuche der modernen Chirurgie, die im Widerspruch mit den physiologischen Grundsätzen und der Praxis stehe; eine zweckmässige orthopädische Behandlung mache sie immer überflussig, und man vermeide so eine verstümmelnde und eventuell lebensgefährliche Operation.

Bei veralteten Fällen und bei Erwachsenen sei eine solche Operation zwar mehr zu entschuldigen, habe aber bisher besondere Vorzüge nicht gezeigt, wohl aber Schattenseiten; endlich lassen sich die Versuche der orthopädischen Tarsotomie bei congenitalem Pes varus durchaus nicht rechtfertigen durch ihre Anwendbarkeit bei Deformitäten entzïndlichen Ursprungs.

Guérin ${ }^{22}$ ) im Jahre 1885 wiederholte seine im Jahre 1882 veröffentlichte Ansicht. Er verwirft jede Knochenoperation bei Behandlung des congenitalen Pes varus; mit subcutaner Tenotomie, passiven Bewegungen und Schienenverbänden komme man bei Kindern immer aus, bei sehr hochgradigen Klumpfussen, besonders Er-

*) Jules Guérin erhielt seiner Zeit mit Bouvier von der französischen Akademie der Wissenschaften für seine Schrift über Orthopädie den Monthyonpreis. 
wachsener, könne man die "Syndesmotomie", wie er die von ihm geiibte subcutane Durchschneidung der Tarsal- und Metatarsalbänder nennt, zu Hïlfe nehmen. Er berichtet über einen 14 jährigen $\mathrm{Pa}$ tienten, bei dem er durch Tenotomie der Achillessehne, der Sehnen des Tibialis ant. und post., des Abductor hallucis und Syndesmotomie des Lig. naviculo-cuboideum die Adduction des Fusses zum Schwinden brachte.

\section{Die operative Methode, welche sich auf die Weichtheile des Fusses beschrinkt, die Phelps'sche Methode.}

Dieselbe wurde von $P$ helps, einem Schüler Say re's, angegeben, wird aber in Deutschland noch wenig geibt. Nach A. Philippson haben Lorenz und Vogt auf die Wichtigkeit der Weichtheile bei Behandlung des Klumpfusses hingewiesen, während neuerdings Phelps dieselben zum ausschliesslichen Angriffspunkt seines therapeutischen Eingreifens gemacht hat.

A. Philippson ${ }^{17}$ ) sagt: „Häufige Recidive nach Knochenoperationen mussten das Augenmerk auf die Weichtheile lenken. - Während Knochen- nnd Gelenkanlagen für die Aetiologie von grossem Interesse waren, wurden die secundären Veränderungen, die geschrumpften Weichtheile, vernachlässigt. Der Erste, der in Deutschland nachhaltig die Aufmerksamkeit auf die nutritiv verkürzten Muskeln richtete, war Paul Vogt. Nach der Keilexcision fand er ein Hinderniss für die Correction an der inneren Fussseite, welches er auf den Tibialis post. bezog und deshalb denselben durchschnitt."

Lorenz stellt in seiner Schrift ${ }^{13}$ ) an verschiedenen Stellen die Schrumpfungen der Sehnen, Bänder und Aponeurosen in den Vordergrund. So sagt er z. B.: "Ausgiebige Bänder- und Sehnenschnitte werden indessen hier (bei Kindern und Halbwïchsigen diesseits der 20er Jahre) in vielen Fällen die Eingriffe auf das Knochengerüst zum Theil ganz überflüssig machen, zum Theil wesentlich einschränken können “, oder: „Der leitende Gedanke wird immer der sein müssen, durch verhältnissmässig rücksichtslose lineäre Trennung der Weichtheile ein streng conservatives Verfahren gegenüber dem Knochengerüst des Fusses zu ermöglichen."

Zum Schluss muss Phleps angeführt werden als ein Autor, der nicht allein den Weichtheilen eine grosse Bedeutung fîr die Beständigkeit der Stellung des Klumpfusses beimisst, sondern dieselben auch zum ausschliesslichen Angriffspunkt der Therapie wählt. - -

Die Phelps'sche Methode gehört in die Gruppe der eigentlichen orthopädischen Behandlungsweisen, die allein als rationell aufzufassen 
sind, insofern nur sie im Fall des Gelingens vollkommen befriedigende Resultate in Bezug auf Form, Grösse und Function des Fusses liefern können."

Phelps glaubt, dass der verkrümmte Fuss durch verkürzte Muskeln und Bänder in dieser abnormen Stellung fixirt werde und dass man nach Entfernung des Hindernisses in den Weichtheilen die Umbildung der deformen Knochen durch Umlagerung der Druckpunkte bewirken könne. Die Phelps'sche Methode ist wie die einfache Tenotomie nur ein Voract in der Behandlung, sie ist weiter nichts, als die von den Orthopäden der alten Schule als nothwendig erachtete ausgiebige und nöthigenfalls zum Oefteren wiederholte Tenotomie und Syndesmotomie, welche anstatt fruher meist subcutan, heute unter dem Schutze der A- und Antiseptik offen ausgefuihrt werden soll. Damit wird die alte Methode in verändertem modernem Gewande wieder in ihre Rechte eingesetzt.

Ueber diese Operation bestanden früher unrichtige Auffassungen. Man glaubte, es handele sich um eine rohe Durchschneidung dicker Weichtheilschichten ohne alle Rücksicht auf die in diesen enthaltenen Muskeln, Nerven und Gefässe. Die Phelps'sche Methode besteht vielmehr in einer sorgfältigen Freilegung und Präparation der am inneren Fussbogen sich spannenden Sehnen und Bänder und einer Durchschneidung derselben. Die in allerjüngster Zeit über diese Methode veröffentlichten Berichte lauten günstig. In Hamburg hat Phelps, dem man a priori, da er Schüler Sayre's ist, rohe Operationen nicht wohl unterlegen durfte, vor einiger Zeit uiber seine Methode genauere Angaben gemacht, und von dort werden von $\mathrm{Sch}$ ede auch anscheinend ganz günstig verlaufene, nach dieser $\mathrm{Me}-$ thode behandelte Fälle mitgetheilt.

Nach Janicke ${ }^{24}$ ) „empfahl Schede im ärztlichen Verein zu Hamburg die von Phelps in New-York herübergebrachte Methode der Klumpfussbehandlung auf Grund eigener dahin gehender Erfahrungen. Dieselbe besteht bekanntlich in der Durchsehneidung der Weichtheile auf der Innenseite des Fusses. Das Verfahren hat Schede so gute Dienste geleistet, dass er dasselbe auch auf die Behandlung anderer Difformitäten (Kniegelenkscontracturen, Dupuytren'sche Contracturen, veraltete Caput obstip.-Fälle) ubertragen hat. Bei älteren Kindern ist es nöthig, noch lange Zeit einen starken Druck auf die Narbe auszuliben, um so auf die veränderten Knochen umformend zu wirken ". 


\section{Schlussbetrachtung.}

Wenn wir die Ergebnisse des vorigen Kapitels näher ins Auge fassen, so geht aus denselben hervor, dass die Mehrzahl der Autoren sich gegen die Keilresection ausspricht, welches Resultat um so beachtenswerther ist, weil zwei dieser Operation ungünstige Urtheile vorliegen, die von Operateuren (Ried und Bessel-Hagen) stammen, die sich also auf ihre an eigenem Material gewonnenen Erfahrungen stïtzen. In der That genuigt es, mit der Keilosteotomie behandelte Füsse in Augenschein zu nehmen, um die Richtigkeit dieser Ansichten anzuerkennen. Seit Kurzem hat Dr. Kraus s die orthopädische Behandlung eines mit doppelseitigem congenitalem Pes varus behafteten und ohne allen Erfolg mit Keilosteotomie behandelten 7 jährigen Knaben begonnen. Es ist, soweit uns bekannt, der erste derartige Fall, wo nach vorausgegangener Keilresection wegen Mangel an Erfolg noch nachträglich die Huilfe der mechanischen Orthopädie nachgesucht wird. Es wird von Interesse sein, zu sehen, was die mechanische Orthopädie unter diesen Verbältnissen noch zu leisten vermag.*)

Hinsichtlich der Talusexstirpation haben die 5 im Vorhergehenden genau beschriebenen Fälle die Erfolglosigkeit dieser Operationsweise gezeigt. Hinzuzufügen ist noch das Urtheil Hirschberg's tiber die beiden auf dem XIV. Chirurgencongress vorgestellten Fälle, wonach also auch selbst die als durchaus nothwendig bezeichnete Durchsehneidung des Lig. calcaneo-fibulare, die in diesen beiden Fällen ausgeführt wurde, nicht zu einem besseren Resultat hat führen können. Wir glauben, dass diese Thatsachen so schwerwiegend sind, um auch in der Talusexstirpation nicht den Weg zur Heilung des Klumpfusses erkennen zu können.

So kommen wir denn an der Hand der Thatsachen zu dem Schluss, uns gegen jeden operativen Eingriff in das Fussskelet erklären zu müssen, und zwar werden wir in der Richtigkeit dieser Ansicht noch mehr bestärkt, wenn wir in Folgendem kurz die Ergebnisse der neuesten Untersuchungen v. Me yer's ${ }^{26}$ ) über die Statik und Mechanik des mensehlichen Fusses zusammenstellen.

„Der auf den Boden aufgesetzte und belastete Fuss gestaltet sich zu einem festen, mehr oder weniger starren Gewölbe, welches stark genug ist, die Schwere des ganzen Körpers zu tragen. Die

*) Der betreffende Knabe ist inzwischen geheilt und ein zweiter derartiger Fall in Behandlung genommen worden. 
Uebertragung der Schwerlast des Körpers geschieht zunächst auf den Astragalus.

Der Fuss ist der Urtypus einer Knochencombination. Die einzelnen Knochen, welche am frei schwebenden Fusse grossentheils sehr lose gegeneinander beweglich sind, stellen in dem Augenblick, in welchem der Fuss belastet auf den Boden gesetzt wird, eine einzige als Einheit wirkende starre Masse dar, und zwar allein infolge des antagonistischen Gleichgewichts zwischen Schwere und Bänderspannung. Als wi chtigster Theil des Fusses erscheint der $T$ al us, der als oberster mit dem Unterschenkel verbundener Knochen beim a ufechten Stehen z unächst die Belastung aufnimmt und sie dann dem übrigen Fuss überträgt, so dass dieser sie wieder dem Boden übertragen kann.

Nimmt man den Astragalus aus einem Fusse beraus, so stellt der übrige Fuss, zunächst die Fusswurzel, einen unvollständigen Ring dar, indem Calcaneus und Naviculare durch eine grosse Liicke von einander getrennt sind. Nur das starke Lig. calcaneo-naviculare schliesst die Lücke ab. Der Calcaneus zeigt eine grosse Beweglichkeit gegen Cuboides und Naviculare.

In dem Sohlenstand nimmt der Fuss die Schwere als ein tragendes Gewölbe auf, dessen Fusspunkte hinten die Tubercula calcanei und vorn die Metatarsusköpfehen sind; die Zehen kommen hierbei nicht zur Geltung. Den Scheitel des Gewölbes bildet der Talus, dieser nimmt die Belastung auf und überträgt sie den beiden genannten Fusspunkten, von welchen sie dann dem Boden übertragen werden."

Nach v. Meyer's Untersuchungen wird das tragende Gewölbe, das Centralgewölbe des Fusses, gebildet durch die Knochenreihe Os metatarsi III, Cuneiforme III, Cuboides und Calcaneus. Als Ergänzung derselben dienen Naviculare und Talus. Durch die Einschaltung des Talus und des durch diesen festgestellten Naviculare erfährt dasselbe eine sehr wichtige Verstärkung und Ergänzung.

"Der Talus", sagt v. Meyer, „ist nach Art eines Schlusssteines $z$ wischen Caleaneus und Naviculare durch die Schwere eingekeilt und wirkt deswegen in diesem Gewölbe mehr anspannend auf einen Theil der Bänder.

In allen 3 Arten der statischen Function des Fusses nimmt der Talus zunächst die Belastung auf und überträgt sie auf die tibrigen Theile des Fusses, wobei er zugleich verschiedene Stellungen einzunehmen hat. Im Sohlenstand stïtzt sich der Talus an 3 Punkten 
(Körper, Processus ant. calc. und Sustentaculum tali) auf den Calcaneus, im Grosszehenstande aber mit seinem Kopf auf den inneren Theil des Naviculare und im Kleinzehenstand ebenfalls mit seinem Kopf auf den äusseren Theil des Naviculare.

Was die Phelps'sche Methode anbetrifft, so ist diese bei uns in Deutschland noch zu neu, um zu einem Urtheil über dieselbe gelangen zu können. Man kann sich einstweilen nur die Frage vorlegen, warum man zu einer offenen Durchschneidung der Sehnen und Bänder in einer Sitzung übergehen soll, wenn man nach der Erfahrung der alten Tenotomen mit der subcutanen sein Ziel gefahrloser erreichen kann?

Unsere Ueberlegungen führen uns also am Schlusse unserer Arbeit zu dem Ergebniss, dass die mechanische Orthopädie das souveräne Heilmittel für den Klumpfuss ist, und zwar nur mit der einzigen Ausnahme, dass es sich um einen anhaltend und in sehr hohem Grade schmerzhaft gewordenen Klumpfuss handelt.

Die pathologische Anatomie lebrt, dass der Knochen da, wo er anhaltendem Druck ausgesetzt ist, atrophirt, da hingegen, wo er anhaltend entlastet wird, verstärktes Wachsthum zeigt. Indem wir die Druckpunkte umlagern, bilden wir das deforme Fussskelet zu einem normalen um. Der auf allen Gebieten der Therapie obenanstehende Grundsatz, die Heilung durch die Kräfte der Natur anzustreben und diese in die richtigen Bahnen zu lenken, muss uns auch Richtschnur in der Therapie des Klumpfusses sein. Dann erzielen wir eine vollkommene Heilung und erhalten Form und Function des Fusses.

Ich schliesse mit den Worten, die mein Vater im Jahre 1839 in seiner Londoner Schrift ${ }^{25}$ ) niederschrieb:

„Prüfe mit Sorgfalt, wende an die entsprechenden Mittel und Kräfte, folge mit wachsamem Auge den Veränderungen der Natur - und zu deiner Verwunderung werden des menschlichen Körpers gestörte Formen sich umwandeln zu Ebenmaass und Wohlgestalt."

\section{Literaturverzeichniss.}

1. König, Lehrbuch der speciellen Chirurgie. Bd. III. 3. Aufl.

2. Hueter, Specielle Chirurgie. III.

3. Dr. Lewis A. Sayre, Vorlesungen über orthopädische Chirurgie und Gelenkkrankheiter. Uebersetzt von Dr. F. Dumont. 2. Aufl.

4. Kö nig, Die Behandlung des Klumpfusses durch Ausschneidung eines Knochenkeiles aus dem Fussrücken. Centralblatt für Chirurgie. 1880. Nr. 13. 
5. Roser, Beitrăge zur Lehre vom Klumpfusse und Plattfusse.

6. Macewen, On the pathology and treatment of congenital Talipes Varus (Medico-chirurg. Soc. 6. March). Glasgow med. Journ. May 1885. Nach VirchowHirsch.

7. Hirschberg, Vortrag auf dem XIV. Chirurgencongress. Verhandlungen der deutschen Gesellschaft für Chirurgie.

8. Wolff, J., Weitere Mittheil. über die Behandlung des Klumpfusses. Ebenda.

9. Vogt, Prof. Dr. Paul, Moderne Orthopädik. 2. Aufl.

10. Dr. Krauss, Ueber den Werth der Resection in der Fusswurzel zur Heilung des Klumpfusses. Verhandlungen d. deutsch. Gesellsch. f. Chir. XV. Congr.

11. Weis s, Pied bot équin accidentel, ablation de l'astragale; guérison. Gaz. des hôp. 1885. No. 32. Nach Virchow-Hirsch.

12. Ried, Dr. Ernst (Jena), München, Weitere Beiträge zur operativen Behandlung des Klumpfusses. Diese Zeitschrift. 1885, 5 u. 6.

13. Bessel-Hagen, Deber die Pathologie des Klumpfusses und über die Behandlung hochgradiger Fälle mittelst der Talusexstirpation. Verhandlungen der deutschen Gesellschaft für Chirurgie. XIV. Congress.

14. Boeckel, E., Traitement des pieds bots vétérés par l'exstirpation de l'astragale. Bullet. de la soc. de chirurg. 18. Avril 1883. Nach Virchow-Hirsch.

15. Nicolaysen, J., Om nogle nyere Behandlingmetoder for Equino-varus. Klinisk Arbog. I. 1884. Kristiania. Nach Virchow-Hirsch.

16. Tillaux, Bull. de l'Acəd. de méd. (Paris) 1882. No. 37. Nach Virch.-Hirsch.

17. Lorenz, A., Ueber die operative Orthopädie des Klumpfusses. Wiener Klinik. 5. u. 6. Heft. Mai, Juni. Wien. Nach Virchow-Hirsch.

18. Wanscher, Behandlingen af de congenite og infantile Foddeférmiteter. Kjöbenhavn. Nach Virchow-Hirsch.

19. Wolff, J. (Berlin), Vorstellung von Klumpfussfällen. Verhandlungen der deutschen Gesellschaft für Chirurgie. XIII. Congress. Nach Virchow-Hirsch.

20. De Forest Williard, Club-Foot. Is excision of the tarsus necessary in children? Philadelphia 1884. Nach Virchow-Hirsch.

21. Guérin, Note sur l'ostéotomie et la tarsotomie dans le traitement du piedbot congénital. Bull. de l'Acad. de méd. No. 37. 1882. Nach Virch.-Hirsch.

22. Guérin, Sur le traitement complémentaire des pieds bots compliqués par la section sous-cutanée des ligaments du pied. Bull. de l'Acad. de méd. 1885. No. 33. p. 1075. Nach Virchow-Hirsch.

23. A. Philipps on, Die Phelps'sche Methode der Klumpfussbehandlung. Diese Zeitschrift. 1887. Bd. XXV.

24. Janicke (Breslau), Referat im Centralblatt für Chirurgie. 1887. Nr. 17, betr. „Schede, Ueber Klumpfussbehandlung“ in Deutsche medic. Wochenschrift. 1886. Nr. 38 .

25. Cure of club-foot, bent knee, wry-neck, spinal, and other deformities with remarks on the late progress of art, and on the necessity of a public institution for the relief of the poor, labouring under deformities by Gustav Krauss, M. D. London, J. Churchill. 1839.

26. Dr. G. Hermann v. Me yer, Statik u. Mechanik des menschlichen Fusses. 1886. 